\title{
Insights into Hydrometeorological Factors Constraining Flood Prediction Skill during the May and October 2015 Texas Hill Country Flood Events $\mathscr{a}$
}

\author{
PEIRONG LIN \\ Jackson School of Geosciences, The University of Texas at Austin, Austin, Texas \\ LARRY J. HOPPER JR. \\ NOAA/NWS Austin/San Antonio Weather Forecast Office, New Braunfels, Texas \\ ZONG-LIANG YANG \\ Jackson School of Geosciences, The University of Texas at Austin, Austin, Texas, and \\ Key Laboratory of Regional Climate-Environment Research for Temperate East Asia, \\ Institute of Atmospheric Physics, Chinese Academy of Sciences, Beijing, China \\ MARK LENZ AND JON W. ZEITLER \\ NOAA/NWS Austin/San Antonio Weather Forecast Office, New Braunfels, Texas
}

(Manuscript received 23 February 2018, in final form 12 July 2018)

\begin{abstract}
This study evaluates the May and October 2015 flood prediction skill of a physically based model resembling the U.S. National Water Model (NWM) over the Texas Hill Country. It also investigates hydrometeorological factors that contributed to a record flood along the Blanco River at Wimberley (WMBT2) in May 2015. Using two radar-based quantitative precipitation estimation (QPE) products-Stage IV and Multi-Radar Multi-Sensor (MRMS) - it is shown that the event precipitation accuracy dominates the prediction skill, where the finer-resolution MRMS QPE mainly benefits basins with small drainage areas. Overall, the model exhibits good performance at gauges with fast flood response from causative rainfall and gauges that are not forecast points in the National Weather Service's Advanced Hydrometeorological Prediction System, showing great promise for forecasts, warnings, and emergency response. However, the model suffers from poor prediction skill over regions without rapid flood response and regions with human-altered flows, suggesting the need to revisit the channel routing algorithm and incorporate modules to represent human alterations. Two contrasting flood events at WMBT2 with similar meteorological characteristics are examined in greater detail, revealing that the location of intense rainfall combined with land physiographic features are key to the flood response differences. Model sensitivity tests further show the record flood peak could be better obtained by tuning the deep-layer soil wetness and the flow velocity field in the river network, which offers hydrometeorological insights into the causes and the complex nature of such a flood and why the model struggles to predict the record flood peak.
\end{abstract}

\section{Introduction and motivation}

Improving forecasts and impact-based decision support for flooding is critical because it is the deadliest severe weather hazard in the United States, with a 10-yr

\footnotetext{
Supplemental information related to this paper is available at the Journals Online website: https://doi.org/10.1175/JHM-D-180038.s1.
}

Corresponding author: Dr. Zong-Liang Yang, liang@jsg.utexas.edu average of over 90 fatalities a year (NWS 2016a). Flood fatality and damage costs continue to increase (Pielke et al. 2002; Downton et al. 2005) as extreme rainfall events become more intense and frequent in the extratropics (Trenberth et al. 2003; Boucher et al. 2013). In flood- and hurricane-prone Texas, climate model runs and analyses show the annual probability of a hurricane producing over $500 \mathrm{~mm}$ of rain increased from $1 \%$ during $1981-2000$ to $6 \%$ in 2017 , with a predicted increase to $18 \%$ by the end of the twenty-first century (Emanuel 2017). Recent catastrophic heavy rainfall and 


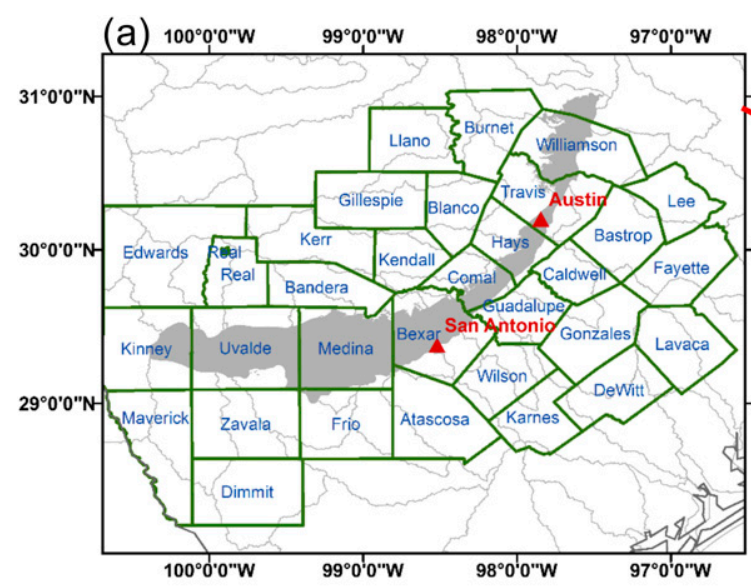

(b)

(c) Channel Slope
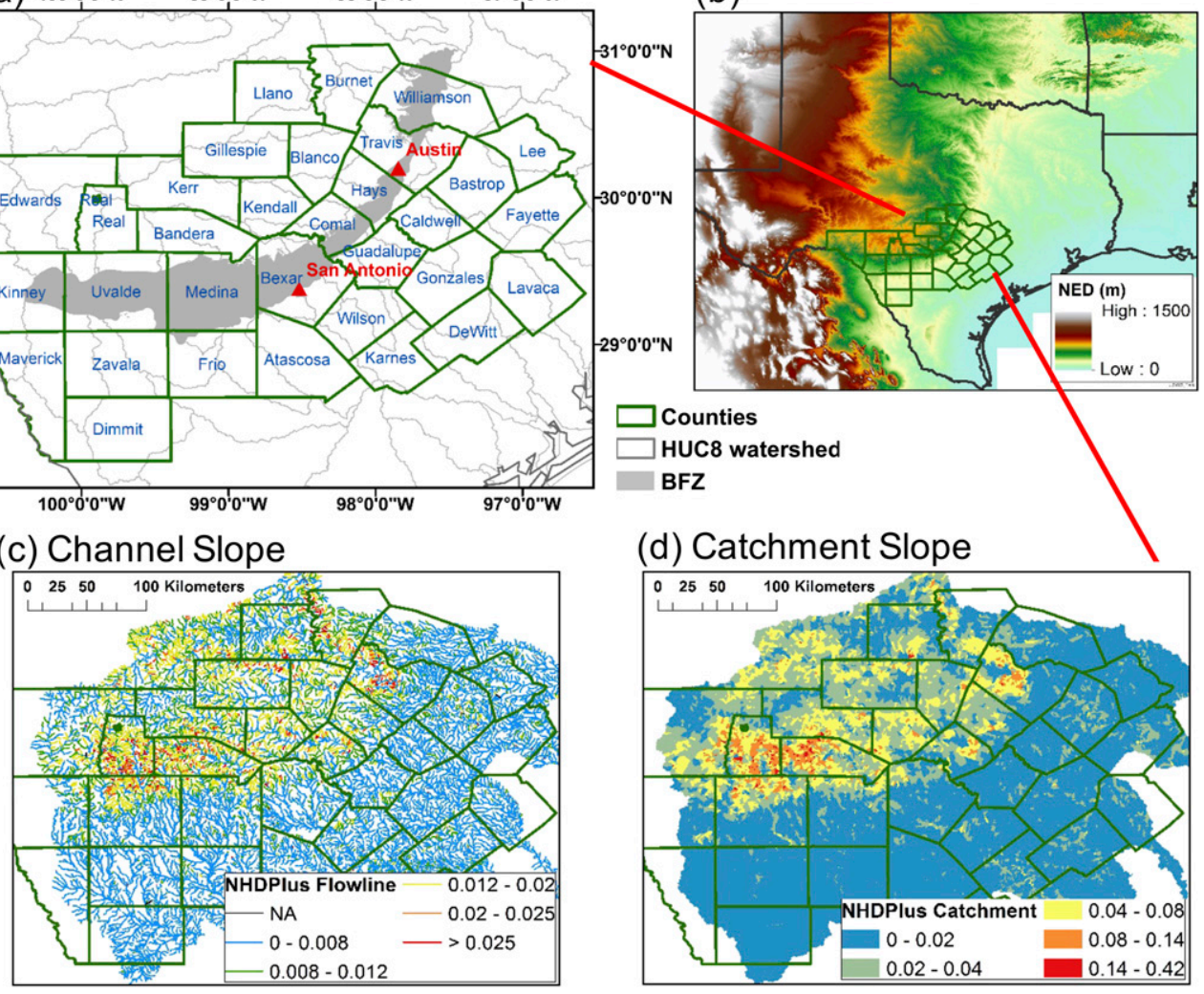

FIG. 1. The modeling domain in south-central Texas: (a) the 33 counties and the Balcones Fault Zone (BFZ) for the location of the Balcones Escarpment, (b) the terrain (m), and the (c) channel slope and (d) catchment slope for the 16906 NHDPlus modeling units.

flood events associated with historic pluvial periods like the spring of 2015 in the southern plains and multiday cases like Hurricane Harvey in August 2017 further underscore the need for better understanding and improving hydrological modeling capabilities.

Improving hydrological prediction is of vital importance to the Texas Hill Country and the Austin-San Antonio corridor, also known as "Flash Flood Alley" because it is one of the most flash flood-prone regions of the contiguous United States (CONUS; Saharia et al. 2017). Intense rain rates frequently occur along the Balcones Escarpment, a limestone terrain uplift separating the $\sim 500$-m-higher Edwards Plateau to the west from coastal plains flowing into the Gulf of Mexico to the southeast (Fig. 1b). The region's vulnerability to simultaneous Gulf and Pacific moisture sources, efficient warm rain processes, and quasi-stationary mesoscale forcing mechanisms enhance orographic lifting to produce sporadic 6-24-h rainfall totals of $250-500 \mathrm{~mm}$. Steep river channel beds and thin soils in relatively small basins with high stream velocities and runoff potentials contribute to rapid river rises (Sharif et al. 2010; Furl et al.
2015, 2018). In addition to the region's complex terrain and soil characteristics, increased urbanization results in even faster river rises and shorter lag times between heavy rainfall and peak discharge than in the downstream coastal plains and most parts of the United States (Leopold 1991; Smith et al. 2000). These aforementioned factors, combined with hundreds of low water crossings and rapid population growth, contribute to significant fatality rates caused by regular shortreturn-period events instead of rare, high-casualty events in other parts of the United States (Ashley and Ashley 2008).

Existing operational hydrological models struggle with accurately simulating the Hill Country's rapid flood response to heavy rainfall, limiting the region's flood preparedness. The lumped-parameter Sacramento Soil Moisture Accounting model (SAC-SMA) does not account for spatial and temporal rainfall variations, whereas a distributed version of the model (Smith et al. 2012) also struggles to produce effective forecasts for small catchments and areas with complex terrain (Zhang et al. 2012). The launch of the National Atmospheric 
and Oceanographic Administration's (NOAA) National Water Model (NWM; http://water.noaa.gov/about/nwm) leverages the Weather Research and Forecasting Model hydrological modeling system's (WRF-Hydro; Gochis et al. 2015) modular structure to couple the Noah land surface model (LSM) with multiparameterization (NoahMP; Niu et al. 2011) with atmospheric models and hydrological routing. The NWM represents an advanced conceptual shift in distributed hydrologic modeling (Maidment 2016) using an Earth system modeling approach (Sivapalan 2018), offering a dramatic increase from $\sim 4000$ forecast points currently with the National Weather Service (NWS) Advanced Hydrologic Prediction Service (AHPS; http://water.weather.gov/ahps/ about/about.php) to real-time flood prediction at over 2.67 million locations. However, the skill of the NWM and similar model configurations during extreme rainfall events is largely unknown.

The primary objective of this study is to evaluate how well a physically based model whose configuration resembles the NWM performs at the regional and local scale in the Hill Country during high-impact flood events. Two heavy rainfall events on 23-24 May 2015 (hereafter, the May event) and 30 October 2015 (hereafter, the October event) whose annual exceedance probabilities $^{1}$ were both less than $0.2 \%$ (1/500; NWS $2015,2016 \mathrm{~b})$ are investigated in this study. The two events produced widespread flooding with record floods at the Blanco River at Wimberley (May event) and Onion Creek at Driftwood (October event), both of which were preceded by very saturated antecedent soil moisture conditions that helped intensify the magnitude and rapid response of the flooding. Multiple "flash flood emergencies" were issued by the NWS Austin/San Antonio Weather Forecast Office (WFO) during both events due to numerous evacuations and high water rescues, along with 13 fatalities in the May event and 5 fatalities in the October event. Using the best available observational constraints, this study also attempts to offer mechanistic insights into the hydrometeorological drivers contributing to the Blanco River's record flood on 24 May 2015, whose peak flood stage exceeded the last record on 28 May 1929 by $3.5 \mathrm{~m}$. These insights are facilitated by comparing the model's local performance during the May record flood and the October 2015 major flood events at Wimberley, and by identifying missing

\footnotetext{
${ }^{1}$ Annual exceedance probabilities for Texas are currently based on Hershfield (1961), but preliminary updates to precipitation frequency estimates for Texas from NOAA Atlas 14, Volume 11, Version 1, that will be finalized and published later in 2018 are available at https://hdsc.nws.noaa.gov/hdsc/pfds/PFDS-Texas/ tx_peer_rev.html.
}

factors in accurately reproducing the flood peak during May that substantially exceeded its previous record.

Finally, this study uses two seamless operational radar-based quantitative precipitation estimation (QPE) products to assess how QPE accuracy influences the uncertainty in simulating streamflow. Therefore, the results are model-observation comparisons of streamflow "simulations" instead of "predictions" that are forced by model-derived quantitative precipitation forecasts (QPFs). Caution should be exercised when applying this study's insights to real-time prediction scenarios, because errors in model-derived QPF may overwhelm those assessed with historical events. Nevertheless, the study's insights into the hydrologic model components of the NWM should provide a better understanding of the complex nature of riverine flash floods, to improve the flood preparedness and resilience to future record-breaking flood events in the Hill Country and regions with similar challenges.

\section{Meteorological descriptions for the 23-24 May 2015 and 30 October 2015 events}

Both flood events exhibit broad meteorological characteristics that have been observed during past heavy rainfall events in the Hill Country. Grice and Maddox (1983) found heavy rainfall occurs most often in late spring or fall with quasi-stationary outflow boundaries left behind by previous convection similar to the May event [i.e., "mesohigh" patterns in Maddox et al. (1979)] or slow-moving "frontal" patterns like the October event. In both events, longwave 500-700-hPa troughs over the western United States digging into Mexico with a leading shortwave moving through Texas enhanced convection along mesoscale boundaries. A 7-yr (2009-15) local study showed these "longwave mesoscale" patterns produce the greatest areal coverage of heavy rainfall, resulting in the highest storm totals at any percentile compared to singular shortwaves or cutoff lows with or without synoptic fronts (Hopper and Hampshire 2016). Only four of these "longwave mesoscale" cases were identified out of 58 events analyzed by Hopper and Hampshire (2016), two of which are investigated in this study.

Similar mesoscale environmental parameters in both events included several ingredients for heavy rainfall. Precipitable water values $(48-53 \mathrm{~mm})$ were over two standard deviations above the mean with a south-southeasterly $20 \mathrm{~m} \mathrm{~s}^{-1}$ low-level jet transporting this moisture nearly orthogonal to the Balcones Escarpment. Relatively low lifting condensation levels and high $-10^{\circ} \mathrm{C}$ levels allowed for $5.0-5.5-\mathrm{km}$ warm cloud layer depths (Schroeder et al. 2016), which enhanced efficient warm rain processes. Despite moderate shear, westerly mesobeta-scale convective elements (Corfidi et al. 1996) that 


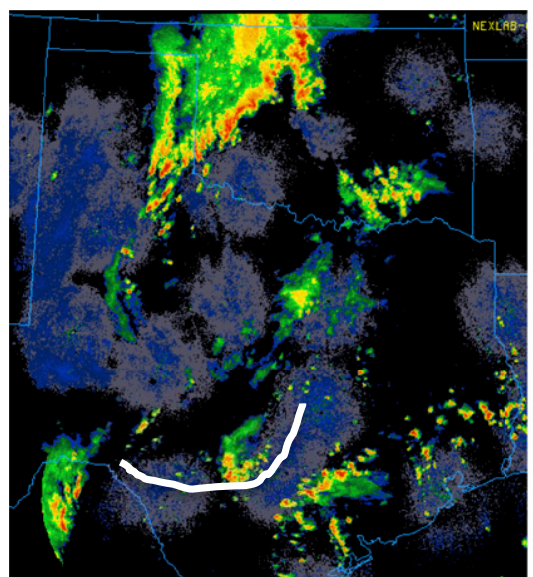

a) 1825 UTE

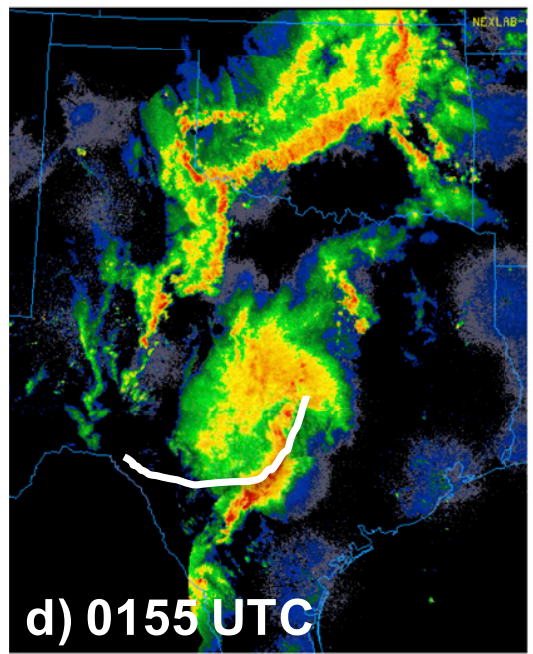

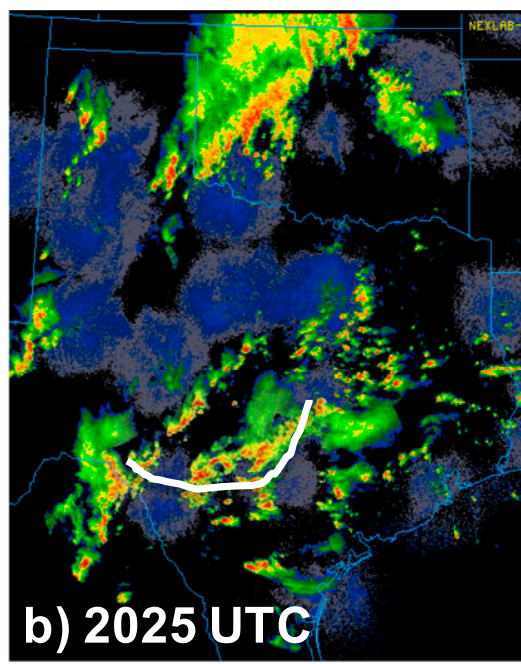

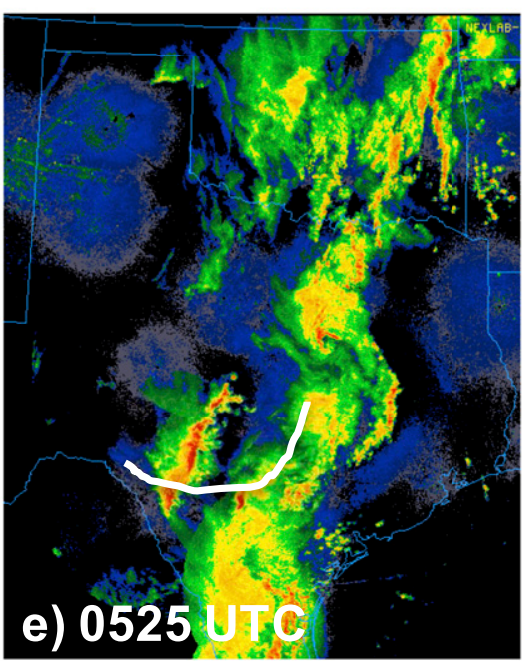

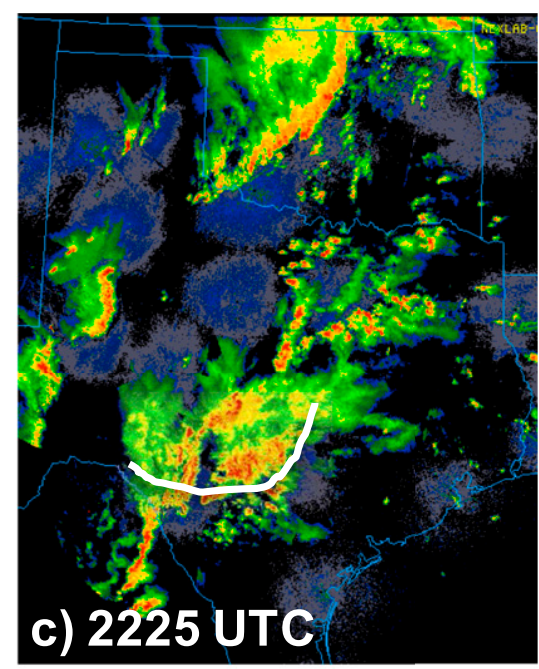

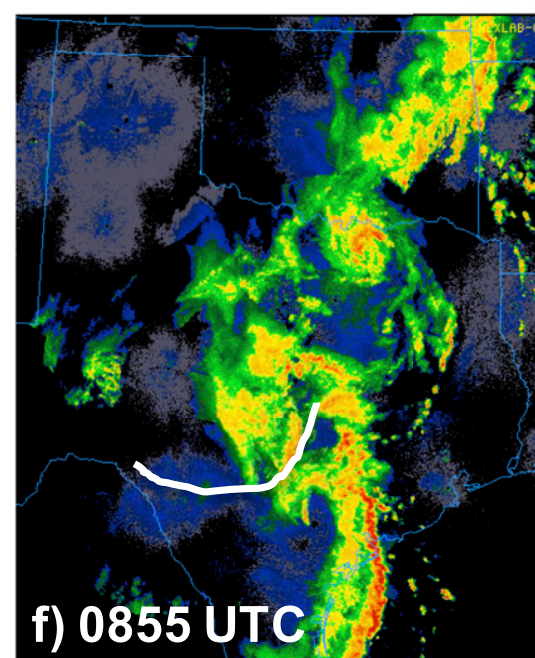

\section{$\mathrm{dBZ}$}

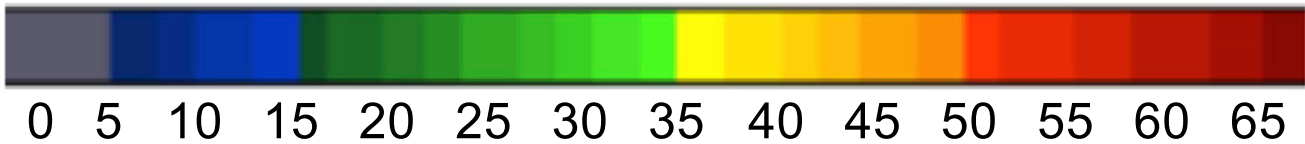

FIG. 2. (a)-(f) Radar composite images at selected times from 1825 UTC 23 May to 0855 UTC 24 May 2015. The white line denotes the approximate location of the Balcones Escarpment. All images are obtained from an online archive maintained by the Mesoscale and Microscale Division of NCAR.

were slower and nearly perpendicular to the mean winds supported "echo training" with back-building and quasi-stationary convective modes (Schumacher and Johnson 2005, 2009), producing heavy rainfall in both events.

Quasi-stationary frontal forcing focused heavy rain in the October event, whereas outflow boundaries and a static mesoscale convective vortex (MCV) concentrated rainfall during the May event that Furl et al. (2018) described in greater detail. During the May event, convection that developed along an outflow boundary in the Hill Country and a sea breeze along the Gulf Coast
(Fig. 2a) merged over Kendall and southern Blanco Counties between 2000 and 2100 UTC 23 May 2015 (Fig. 2b). A quasi-stationary MCV that developed here by 2100 UTC encouraged cell mergers to maintain $51-102 \mathrm{~mm} \mathrm{~h}^{-1}\left(2-4\right.$ in. $\left.\mathrm{h}^{-1}\right)$ rain rates near the $\mathrm{MCV}$ through 0100 UTC 24 May 2015 before combining with a line of storms that moved in from Mexico (Figs. 2c,d). One final convective line that developed along the west Texas dryline progressed across the region from 0300 to 1000 UTC (Figs. 2e,f). During the October event, convection developed between 0600 and 0800 UTC 30 October 2015 (Fig. 3a) over the Rio Grande Plains, 

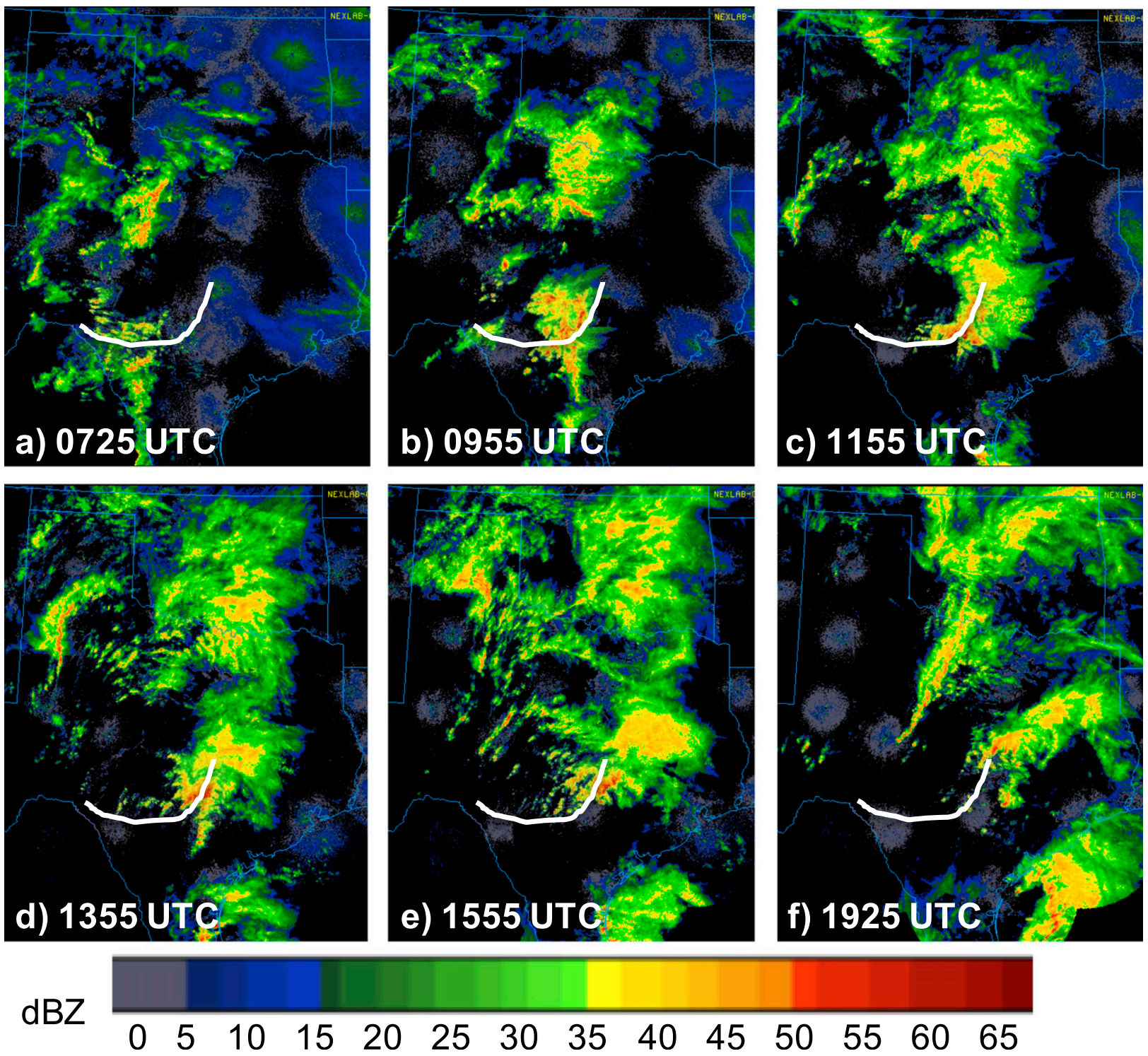

FIG. 3. As in Fig. 2, but from 0725 to 1925 UTC 30 Oct 2015.

intensifying as it moved east into a strengthening lowlevel jet in the Hill Country through 1000 UTC (Fig. 3b). Discrete supercells that developed along the warm front fed a back-building, quasi-stationary line of convection from 1100 to 1530 UTC (Figs. 3c,d). These convective echoes trained northeast along the front that stalled nearly parallel to the Balcones Escarpment, with $178 \mathrm{~mm}$ (7.02 in.) of rain observed from 1405 to 1505 UTC along Onion Creek at Highway 183. A stronger downdraft and associated cold pool finally propagated these cells northeast after 1530 UTC (Fig. 3e) before they moved east of the study domain by 1925 UTC (Fig. 3f). The October event's heavier and more focused rainfall caused its Stage IV (hereafter ST4) QPE to nearly double the
May event's areal coverage ( $656 \mathrm{vs} 336 \mathrm{~km}^{2}$ ) of rain totals over $152 \mathrm{~mm}$ (6in.), but the May event had more widespread (3040 vs $2032 \mathrm{~km}^{2}$ ) rain totals over $76 \mathrm{~mm}$ (3in.).

\section{Model, experiments, and data}

\section{a. Study domain}

Our modeling domain covers south-central Texas with an area of $91571.3 \mathrm{~km}^{2}$ (Fig. 1a). This domain is determined based on the intersected areas between the Hydrologic Unit Code-8 (HUC-8) watershed boundaries and 33 counties with the NWS Austin/San Antonio WFO (Fig. 1b), where two major cities (i.e., Austin and San Antonio) are located. The domain incorporates 16906 
TABLE 1. Comparison between the model configuration of this study and the NWM. Only the historical/analysis configuration of the NWM is shown here; the short-, medium-, and long-range forecast configurations have some variations due to computational considerations.

\begin{tabular}{|c|c|c|}
\hline & This study & NWM \\
\hline \multicolumn{3}{|c|}{ Physical model chain } \\
\hline Noah-MP LSM & \multirow{2}{*}{\multicolumn{2}{|c|}{$\begin{array}{l}\text { Same physical parameterization options (1-km resolution) } \\
\text { MC routing based on NHDPlusV2; channel trapezoidal parameters obtained from http://water.noaa.gov/ } \\
\text { about/nwm }\end{array}$}} \\
\hline Channel routing & & \\
\hline \multirow[t]{2}{*}{ Overland flow routing } & Overland delay functions (see appendix) & Diffusive overland routing based on a $250-\mathrm{m}$ grid \\
\hline & \multicolumn{2}{|c|}{ Other modeling capabilities } \\
\hline Reservoirs & Not represented & Simple level-pool routing with 1260 major reservoirs in CONUS \\
\hline Data assimilation & No DA performed & Nudging-based DA with $\sim 7000$ gauges in CONUS \\
\hline
\end{tabular}

National Hydrography Dataset Plus (NHDPlus) river reaches and catchments, where a clear distinction in channel bed slope (Fig. 1c) and catchment slope (Fig. 1d) between the western and eastern sides of the Balcones Escarpment is displayed. Channel slope is the slope along the river channel for the channel flow velocity calculation, which is pre-established with the NHDPlus flowline attribute table. Catchment slope is the slope toward (or perpendicular to) the channel, which is calculated based on terrain analyses and is used to estimate the overland flow velocity (see appendix).

\section{b. Model descriptions and augmentations}

Under the modular architecture of WRF-Hydro, the Noah-MP LSM is tightly coupled to a vector-based river routing model (RAPID; David et al. 2011) to simulate the flood discharges (hereafter WRF-Hydro-RAPID). Noah-MP is a state-of-the-art LSM originally developed for numerical weather predictions (NWPs) for vertical representation of hydrological processes. It is now used for physically based, spatially distributed hydrologic simulations with the NWM. RAPID is built upon the NHDPlus vector flowline network, which is the common geospatial framework adopted by the NWM. Because the NWM was in initial implementation as this project started and is under continuing development, we adopt the following strategies so that our results may be generalized within the conceptual framework of the NWM. First, the same Noah-MP parameterization options adopted by the NWM are used, including the freedrainage runoff option where surface runoff is calculated as excess water after precipitation supply infiltrates into the soil (Schaake et al. 1996). Infiltration within the four soil layers is solved using the Richards equation with the layer thicknesses of $10,30,60$, and $100 \mathrm{~cm}$, respectively. Subsurface runoff is calculated as the gravitational free-drainage from the bottom soil layer (Niu et al. 2011). Other hydrological processes are described in Yang et al. (2011), Cai et al. (2014), and Zheng and Yang (2016). Second, we augment the hydrological routing of the WRF-Hydro-RAPID model (see appendix for details) by implementing 1) a time-variant overland flow delay function and 2) the Muskingum-Cunge (MC) channel routing using the same channel trapezoidal parameters obtained from the operational NWM.

Table 1 provides a detailed comparison between the model configuration of this study and the NWM, which mainly differ in how reservoirs and overland routing processes are treated. Although our model configuration produces streamflow simulations at all available NHDPlus river reaches, we remove gauges downstream of reservoirs for evaluation purposes, because reservoir operations are not accounted for in our model configuration, unlike the NWM, which allows for simple level-pool schemes for 1260 major reservoirs. Sensitivity tests (not shown) with the delay function used in this study (see the appendix) suggest that the overland flow concentration time during major floods is often very short using NHDPlus catchments as the modeling units $(<100 \mathrm{~s})$, which minimally influences the simulated flood hydrographs. Therefore, the results here should have general implications to the NWM and other similar model configurations.

In this study, the model results are not calibrated, meaning the parameters used are either directly linked to the land surface physical properties or estimated using widely documented empirical values in the literature. Manning's roughness coefficients are also obtained from the operational NWM. Although model calibration is a common practice for most hydrological studies, this study does not calibrate because of the increasing awareness of the "equifinality" problem, suggesting correct answers could be achieved for wrong reasons (Beven 2006). In addition, assessing a physically based model with minimal calibration may be more informative in actual prediction scenarios, as they do not need to rely on historical data and the potentially incorrect assumption on hydrological stationarity (Milly et al. 2008) necessary for calibration. Although calibration is expected to benefit local gauges for engineering hydrology accuracy (Cho and Engel 2017), the goal of 
TABLE 2. Experiments and model configuration of this study.

\begin{tabular}{|c|c|c|c|c|}
\hline & Experiments & Precipitation & Configuration & Spinup \\
\hline May 2015 & $\begin{array}{l}\text { ST4 } \\
\text { Q3GC } \\
\text { Q3RAD }\end{array}$ & $\begin{array}{l}\text { Stage IV QPE } \\
\text { MRMS gauge-corrected QPE } \\
\text { MRMS radar-only QPE }\end{array}$ & $\begin{array}{l}1 \mathrm{~km} \text { and } 1 \mathrm{~h} \text { for } \mathrm{LSM} ; 120 \mathrm{~s} \\
\text { for routing }\end{array}$ & $\begin{array}{l}\text { Initialized on } 1 \text { Apr and } \\
\text { spinup to } 22 \text { May }\end{array}$ \\
\hline October 2015 & $\begin{array}{l}\text { ST4 } \\
\text { Q3GC } \\
\text { Q3RAD }\end{array}$ & $\begin{array}{l}\text { Stage IV QPE } \\
\text { MRMS gauge-corrected QPE } \\
\text { MRMS radar-only QPE }\end{array}$ & $\begin{array}{l}1 \mathrm{~km} \text { and } 1 \mathrm{~h} \text { for LSM; } \\
120 \mathrm{~s} \text { for routing }\end{array}$ & $\begin{array}{l}\text { Initialized on } 1 \text { Sep and } \\
\text { spinup to } 28 \text { Oct }\end{array}$ \\
\hline
\end{tabular}

this study is to gain a process-based understanding toward the model prediction skill at regional to local scales in an objective assessment.

\section{c. Precipitation forcing: Radar-based QPE products}

The ST4 (Lin 2011) and Multi-Radar Multi-Sensor (MRMS; Zhang et al. 2016) radar-based QPE datasets are used as the precipitation forcing inputs. ST4 has been the benchmark operational QPE over the past two decades, which has a 4-km and 1-h spatiotemporal resolution and is processed and quality controlled by hydrologists at 13 regional NWS River Forecast Centers (RFCs). In comparison, MRMS, which became operational in 2014, is automatically generated at a centralized location. One prominent feature of MRMS is its increased spatiotemporal resolution at $1 \mathrm{~km}$ and $2 \mathrm{~min}$ covering the CONUS. In this study, the benchmark ST4 QPE, the MRMS gaugecorrected (Q3GC), and the radar-only (Q3RAD) QPE products are utilized and evaluated due to their operational relevance and data availability.

\section{d. Experimental design and model configurations}

Three experiments are conducted for each event and are named after their precipitation forcing input datasets (see Table 2). All experiments are configured at $1-\mathrm{km}$ resolution (in total $377 \times 477$ grid cells). The LSM and routing time steps are $1 \mathrm{~h}$ and $120 \mathrm{~s}$, respectively. David et al. (2011) suggested a routing time step of $900 \mathrm{~s}$ for the stability criteria $c \Delta t \leq \Delta L$ based on a median wave celerity $c$ of $2.5 \mathrm{~m} \mathrm{~s}^{-1}$ and a median reach length of $2.4 \mathrm{~km}$, where $c$ does not vary with time. This study uses, based on time-variant $c$ with the MC, a much finer routing time step $(120 \mathrm{~s})$ to allow for a maximum $c$ of $20 \mathrm{~m} \mathrm{~s}^{-1}$ for a median-length river reach, the stability of which was demonstrated for our simulations.

The two flood simulations start on 1 April 2015 and 1 September 2015 for the May and October events, respectively. The soil moisture initializations are interpolated from the four-layer Noah LSM outputs of the North American Land Data Assimilation System 2 (NLDAS-2; $1 / 8^{\circ}$; Xia et al. 2012). Although soil moisture in different LSMs may not be directly used from one model to another (Koster et al. 2009), we use this initialization strategy because Noah and Noah-MP are similar in many ways and a spinup of over 50 days may help alleviate such problems. ST4 is used for the model spinup period until 2 days before each event when different QPEs take place. Other forcing variables (radiation, temperature, humidity, wind, and pressure) are obtained from the NLDAS-2 forcing data.

\section{e. Reference in situ measurements for evaluation}

All best-available observational datasets are used to evaluate the model performance and obtain comprehensive quantitative assessment. These gauged datasets include 1) daily precipitation reports from the Community Collaborative Rain, Hail and Snow Network (CoCoRaHS) and the Cooperative Observer Program (COOP) sites, 2) hourly precipitation intensity data from the NWS Hydrologic Automated Data System (HADS), 3) quality-controlled United States Geological Survey (USGS) river discharge data, and 4) indirect USGS discharge measurements during gauge failures (see acknowledgments). CoCoRaHS is a dense rain gauge network collecting daily reports from trained volunteers (Reges et al. 2016). Although these datasets can be subject to uncertainties, such as the CoCoRaHS data collection timing that may vary from user to user for a few hours (Qi et al. 2016), and some gauged data may be ingested in the radar QPE products (Zhang et al. 2016), fully addressing this uncertainty is beyond the scope of this study, and we have carefully used these datasets as independent references (see section 4a) to satisfy our evaluation purposes.

In the study domain, $847 \mathrm{CoCoRaHS}, 127 \mathrm{COOP}$, and 138 HADS gauges are utilized for precipitation evaluation (Figs. 4a,b). Fifty-one USGS Gage-II sites that are not located downstream of reservoirs (out of the original 112 gauges; Fig. 4c) are used in discharge evaluation because the presented modeling framework does not account for reservoir operations. These 51 gauges are further separated into 27 forecast points (i.e., gauges with existing NWS AHPS flood prediction capability) and 24 nonforecast points. USGS also separates "referenced" and "nonreferenced" gauge types, where 21 are classified as referenced (i.e., gauges located in natural river basins; 
(a)

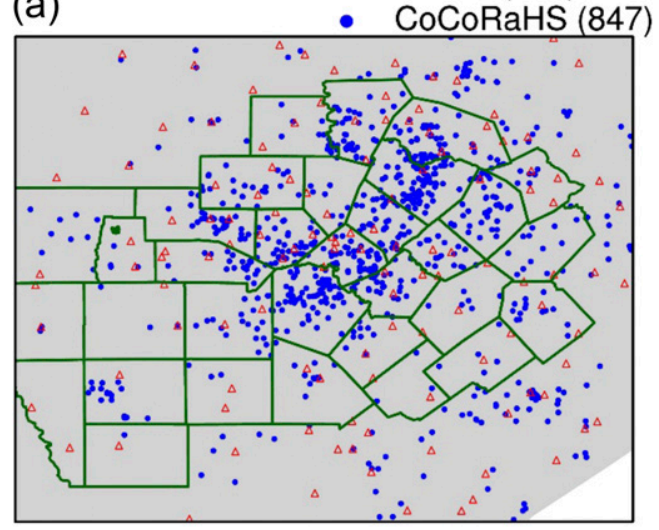

(c)

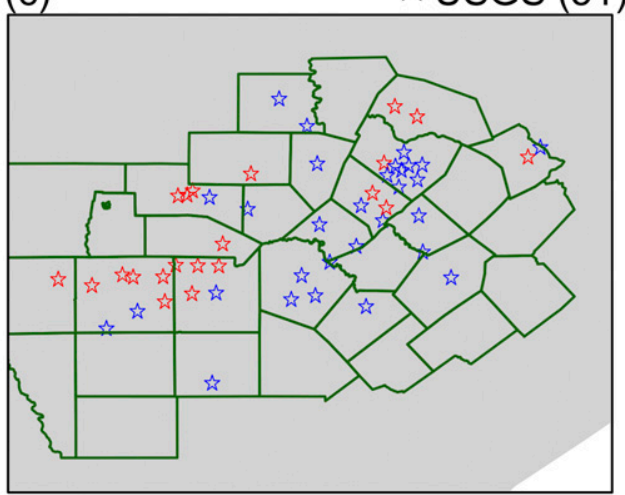

(b)

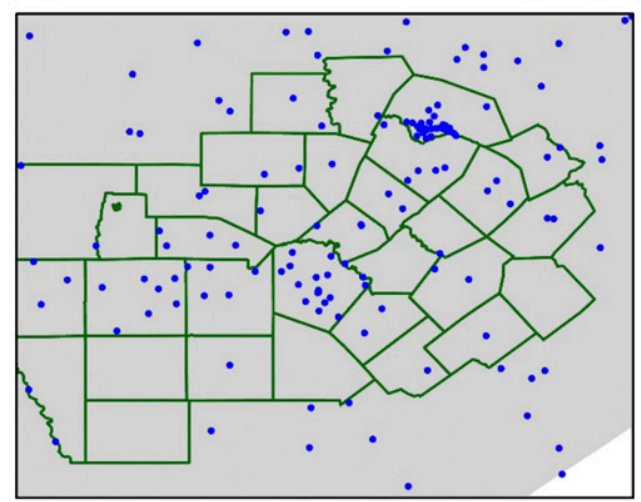

(d)

Radar Coverage

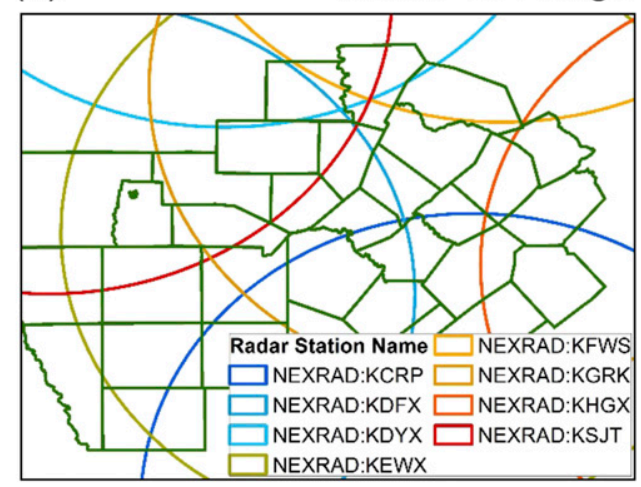

FIG. 4. Available in situ measurements within the modeling domain. (a)-(c) The location of gauges reporting 24-h precipitation, hourly precipitation, and discharge measurements (red: referenced; blue: nonreferenced), respectively, where the total number of available gauges is shown in the parentheses. (d) The maximum radar coverage within the domain.

red in Fig. 4c) and 30 as nonreferenced (i.e., gauges located in basins with human alterations; blue in Fig. 4c) to help delineate regional flood prediction skill in section 4c. The radar coverage map of our study domain is also displayed in Fig. 4d.

\section{Regional and local flood prediction skill \\ a. QPE evaluation}

\section{1) EVENT ACCUMULATED PRECIPITATION}

We first assess the event total precipitation against gauge observations. Figure 5 shows the scatterplot of accumulated precipitation between radar QPE and gauge observations, in which a pair of estimates (i.e., $\mathrm{R} / \mathrm{G}$ pair) is accounted only when both of them are nonzero (Qi et al. 2016). To minimize the influence of CoCoRaHS gauge-reading time that may vary for a few hours around 1200 UTC, the scatterplots show a 24-h period (from 1200 UTC 23 May to 1200 UTC 24 May
2015) for the May event and a 48-h period (from 1200 UTC 29 October to 1200 UTC 31 October 2015) for the October event that capture rainfall for both events in their entirety. Statistics to quantitatively assess the QPE uncertainty include bias ratio (BR; sum of radar QPE divided by sum of gauged precipitation), correlation coefficient (CC), and root-mean-square error (RMSE). $B R$ values of 1 indicate a perfect match between the $\mathrm{QPE}$ and gauged data, whereas $\mathrm{BR}>1(\mathrm{BR}<1)$ suggests an overestimation (underestimation) by QPE.

All QPE sources exhibit reasonable accuracy in capturing the both events' accumulated precipitation based on the range of their BR (0.86-1.11), CC (0.82-0.94), and RMSE (17.87-32.02 $\mathrm{mm}$ day $\left.^{-1}\right)$. MRMS consistently has lower estimates (lower BR) than ST4 for both events, but other statistics vary. ST4 has the best accuracy (Fig. 5a; BR closest to 1 and lowest RMSE) in the May event, whereas MRMS Q3GC (Fig. 5b) and Q3RAD (Fig. 5c) underestimate rainfall totals $(\mathrm{BR}<1)$. However, for the October event where ST4 (Fig. 5d) tends to overestimate, 

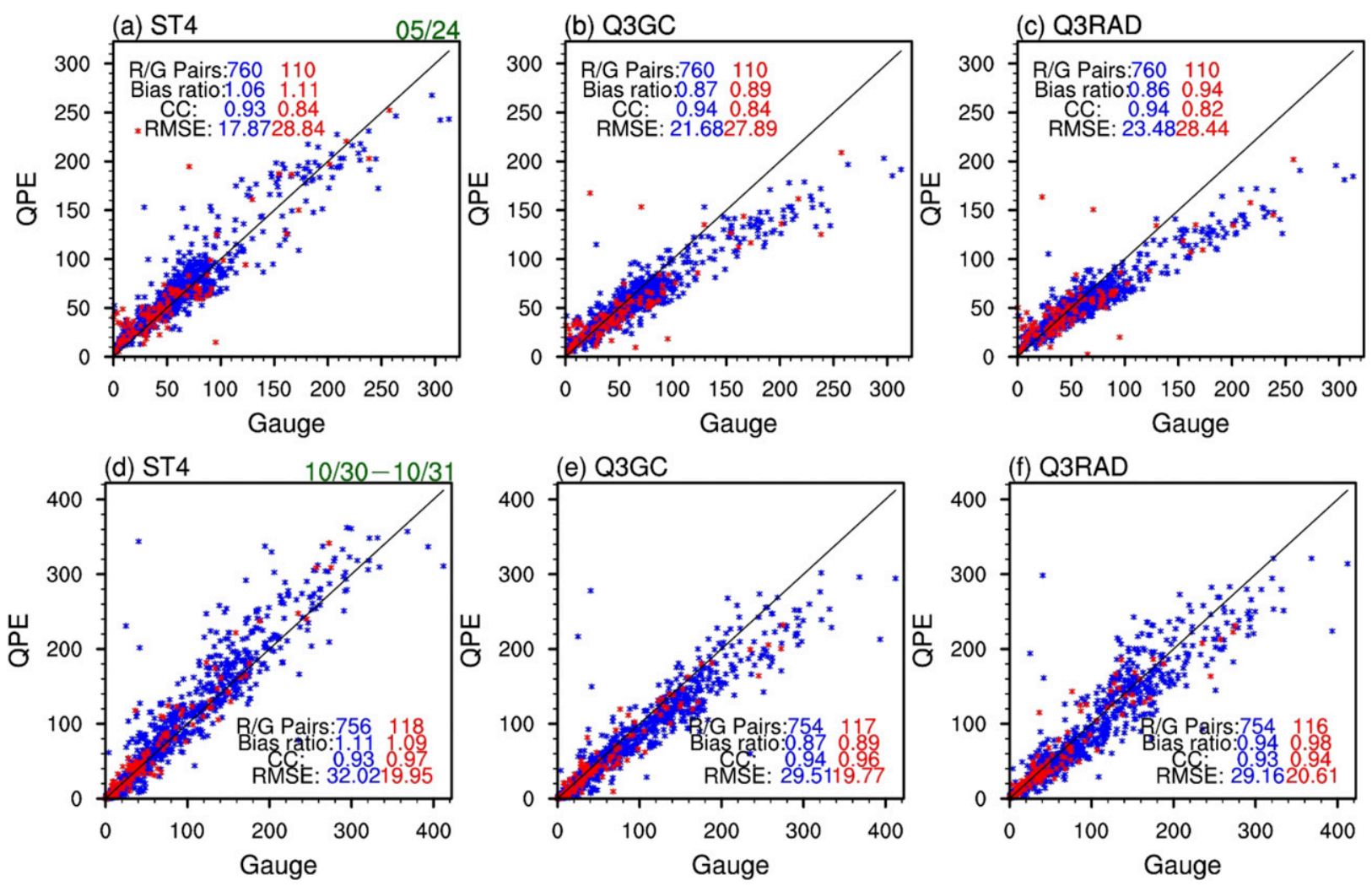

FIG. 5. Scatterplot for accumulated precipitation $(\mathrm{mm})$ between radar QPEs ( $y$ axis) and gauge observations $(x$ axis). (a)-(c) The 24-h accumulation for the May event and (d)-(f) the 48-h accumulation for the October event; the cycle starts and ends at 1200 UTC. Blue and red colors represent CoCoRaHS and COOP observations, respectively.

Q3GC (Fig. 5e) and Q3RAD (Fig. 5f) both display better accuracy by reducing the positive bias. MRMS reduces the RMSE by $\sim 18 \mathrm{~mm}^{-1 a y}{ }^{-1}$ (not shown) during the October event in areas where the heaviest rainfall occurred, which partly explained the better accuracy of MRMS during that event. Overall, the accuracy of Q3RAD (the radar-only MRMS product) is comparable to ST4 and Q3GC (the gauge-corrected MRMS product), which is promising considering Q3RAD does not require time for quality controls like ST4 and Q3GC (Cocks et al. 2016). However, Q3GC still demonstrates better accuracy than Q3RAD for the May event, suggesting there are areas for the MRMS automatic algorithm to be improved to meet finescale accuracy needs.

\section{2) MAXIMUM PRECIPITATION INTENSITY}

The maximum precipitation intensity (MPI; $\mathrm{mm} \mathrm{h}^{-1}$ ) is assessed in Figs. 6 and 7, which is calculated as the maximum hourly rain rate at each pixel over the time period indicated in the figure captions. MPI is important as it is directly linked to the flood peak simulation and is therefore analyzed here in addition to the rainfall totals. The May event has widespread MPI of $40-50 \mathrm{~mm} \mathrm{~h}^{-1}$ for over 10 counties, and all QPEs can reproduce the general patterns and magnitude for several localized heavy rainfalls. However, MRMS (particularly Q3RAD in Fig. 6c) fails to capture the most intense rainfall rates in excess of $60 \mathrm{~mm} \mathrm{~h}^{-1}$, where a scatterplot analysis (Fig. 6e) shows that the hourly Q3RAD MPIs are no greater than $42 \mathrm{~mm} \mathrm{~h}^{-1}$. To understand the underestimation for the May event, we conducted a radar and statistical analyses using 2-min Q3RAD data (not shown) and found that the problem is primarily caused by a truncation of rain rates at $1.78 \mathrm{~mm}$ per $2 \mathrm{~min}\left(53.4 \mathrm{~mm} \mathrm{~h}^{-1}\right)$ where the MRMS algorithm suspects there is hail contamination [i.e., maximum estimated size of hail (MESH) greater than 0]. Readers may refer to Zhang et al. (2016) for more details about MRMS's algorithmic dependence on MESH and other parameters. Other possible causes for the underestimation may include 1) insufficient low-altitude radar coverage to capture orographic enhancement and more efficient, tropical-like warm rain processes, and 2) the model analysis being too coarse to resolve locally moist tropical air masses (i.e., probability of warm rain greater than $50 \%-70 \%$ ). MRMS developers who assisted with our analysis are now implementing a new 
(a) ST4

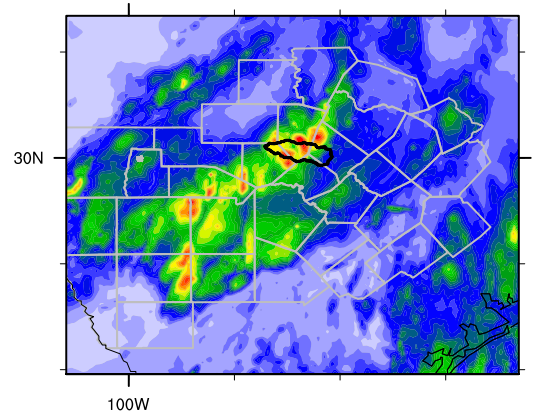

(c) Q3RAD

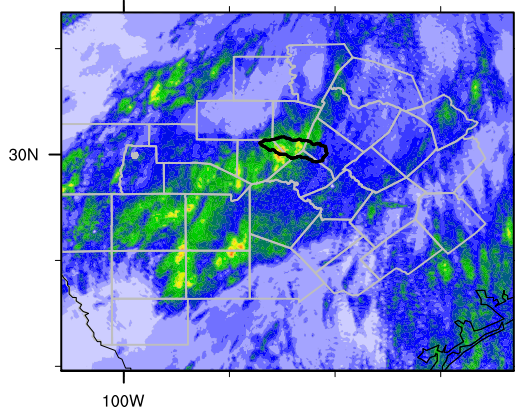

(b) Q3GC

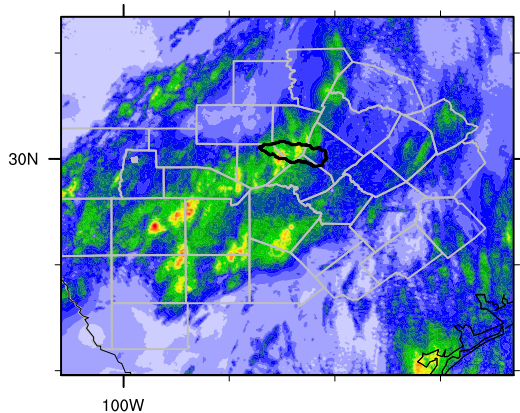

(d) Gauge

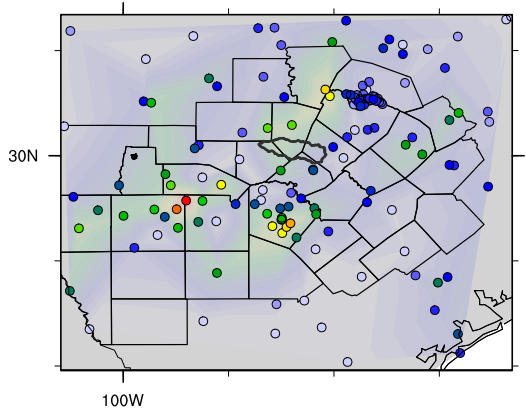

(e) Scatter plot

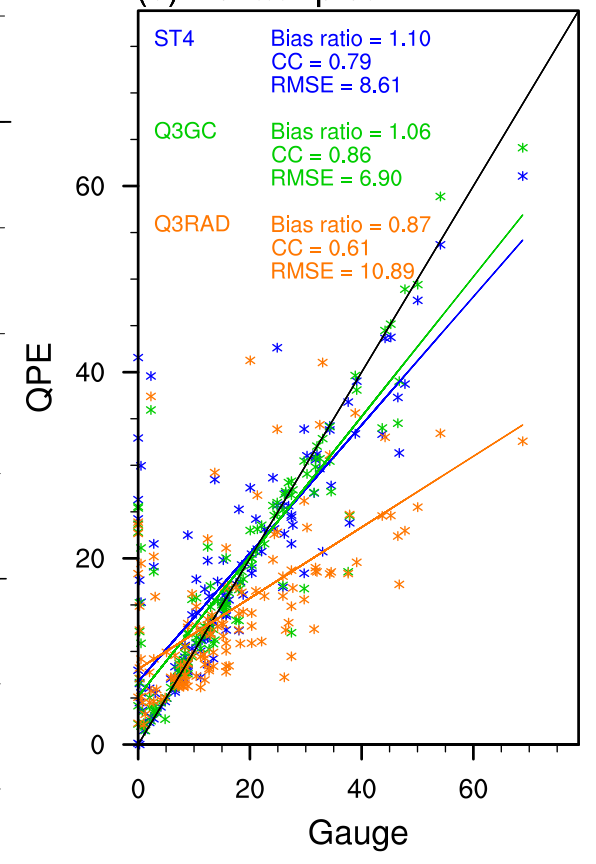

\begin{tabular}{llllllllllllllllll|l|l|l|l|l|l}
0 & 3 & 6 & 9 & 12 & 15 & 18 & 21 & 24 & 27 & 30 & 33 & 36 & 39 & 42 & 45 & 48 & 51 & 54 & 57 & 60
\end{tabular}

FIG. 6. The MPI $\left(\mathrm{mm} \mathrm{h}^{-1}\right)$ for the May event from 1200 UTC 23 May to 1200 UTC 24 May 2015. The spatial distribution of MPI in (a) ST4, (b) Q3GC, (c) Q3RAD, and the (d) HADS gauges. (e) The scatterplot along with regression lines and statistics displayed (the black line indicates the 1:1 line).

dual-polarization QPE algorithm to reduce the MRMS algorithmic dependences on MESH (J. Zhang 2018, personal communication), and we expect these improved QPE inputs will address this underestimation problem for use and evaluation in future studies. For the October event (Fig. 7), the rainfall was much more intense where large areas in Comal, Hays, and Travis Counties observed MPIs over $80 \mathrm{~mm} \mathrm{~h}^{-1}$. Although all QPEs captured the major extreme rainfall band reasonably well, their accuracy still suffers in the lower rain rate range $\left(<50 \mathrm{~mm} \mathrm{~h}^{-1}\right.$, Fig. 7e), where QPEs tend to overestimate rainfall possibly related to false echoes. During this event, Q3GC (Figs. 5e, 7b) has the best accuracy in terms of both the event rainfall totals and the MPIs, which is translated into better regional flood prediction skill shown in section $4 \mathrm{~b}$ that follows.

\section{b. Regional-scale flood prediction skill}

To understand the flood prediction skill from a regional perspective, in this section we show the NashSutcliffe efficiency (NSE) skill metrics (Gupta et al. 2009) at 51 gauges over south-central Texas (Fig. 8). Note that the model provides streamflow simulations at all of the 16906 river reaches (cf. Fig. 1c), but only values for the 51 qualified gauges (see section 2e) are extracted for model evaluation purposes. The NSE is an integrated measure of the model skill that is commonly used to measure how well a model simulates the observed hydrograph. Metrics to assess differences in the flood peak timing and magnitude are shown in Figs. S1 and $\mathrm{S} 2$ in the online supplementary material. Because their spatial patterns generally follow that of Fig. 8 (i.e., gauges with the highest NSEs also show the least errors in peak timing and magnitude), we consider NSE to be a suitable metric for evaluating regional model performance here. Regardless of which QPE is used in either event, the best flood predictive skill (based on NSE > 0.4 in Fig. 8) tends to be observed in regions receiving the most intense and greatest rainfall totals (cf. Figs. 6 and 7). This is very important to the strategic goals of the NWS operations, as the presented model clearly shows promise for flood prediction over the Hill Country where the most extreme rainfall and rapid river rises are observed. A graphical assessment of these simulated flood hydrographs is shown in section $4 \mathrm{~d}$.

However, the model skill is not as good over gauges that do not receive heavy rainfall for fast flood responses (see negative NSEs in Fig. 8). A further examination 
(a) ST4

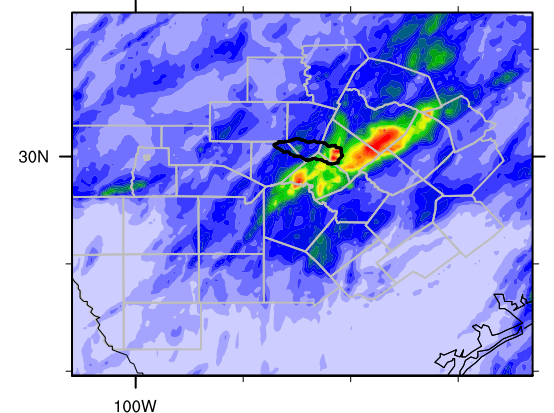

(c) Q3RAD

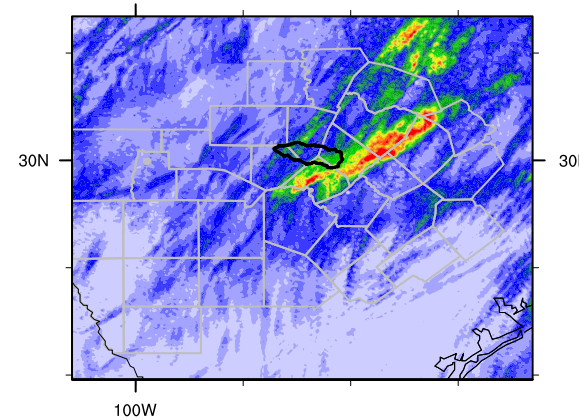

$100 \mathrm{~W}$ (b) Q3GC

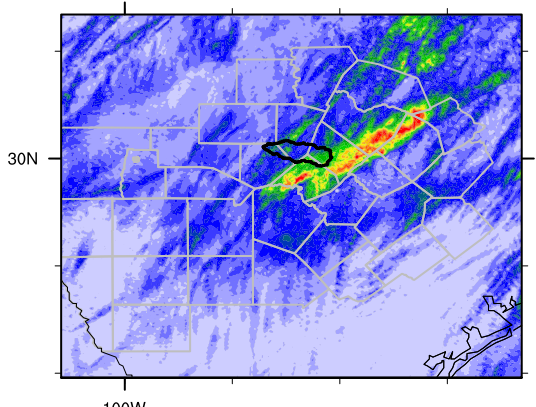

(d) Gauge

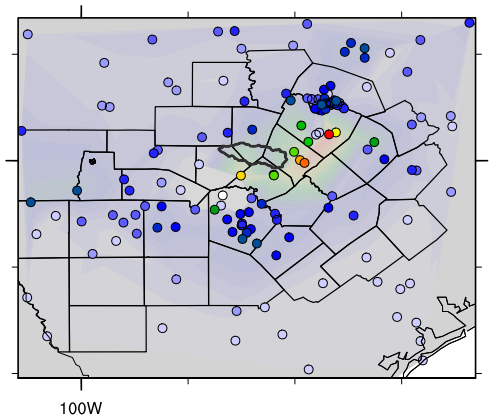

(e) Scatter plot

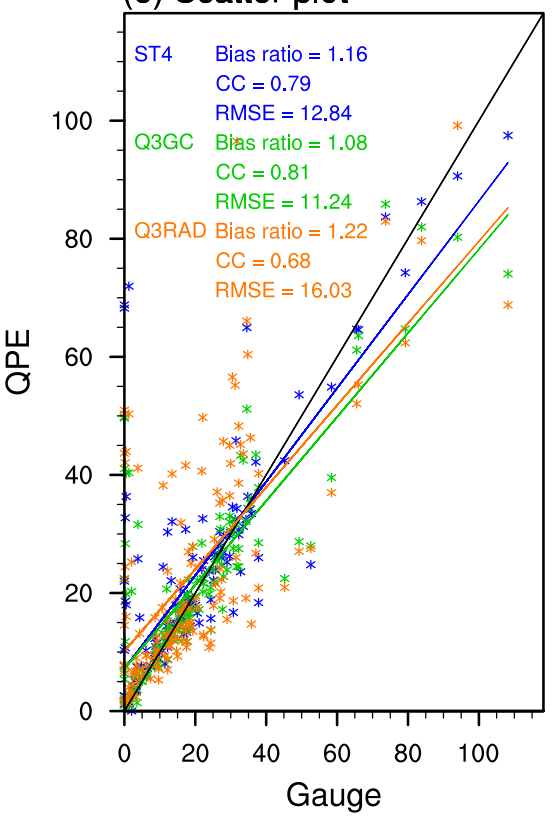

$\begin{array}{lllllllllllllllllllll}0 & 5 & 10 & 15 & 20 & 25 & 30 & 35 & 40 & 45 & 50 & 55 & 60 & 65 & 70 & 75 & 80 & 85 & 90 & 95 & 100\end{array}$

FIG. 7. As in Fig. 6, but for the October event from 0000 UTC 30 Oct to 2300 UTC 31 Oct 2015.

suggests that different error sources could lead to the unsatisfactory discharge simulations. First, river discharge over regions with low rainfall totals can be dominated by baseflow. Four out of the 20 worstperforming gauges have consistently overestimated baseflow (not shown), which may point to the Noah-MP baseflow calculation problems needing future development and calibration. Second, other gauges with low NSEs almost always observe simulated flood hydrographs with more flashy and earlier peaks, which is a common problem also seen in the operational NWM (D. J. Gochis 2017, personal communication). MC routing can be subject to $8 \%-10 \%$ mass balance errors over flat areas (Todini 2007), which may partially explain the poor performance in parts of our domain. In addition, the earlier flood peaks indicate the model may have overestimated flood wave celerity $c$ that may lead to an underestimated channel travel time $k$. In MC, $c$ is a function of predicted discharge $Q$, channel geometry, a factor $\beta$, and Manning's roughness coefficient (see appendix for MC details). These factors are all subject to uncertainties because the presented model uses the crude trapezoidal geometry assumptions and a simple but likely too large $\beta$ factor. Moreover, no floodplains are represented in the model to buffer imminent flood waves. Because flow velocity and flood wave celerity are often the most poorly understood and least observed variables (McDonnell and Beven 2014), their physical parameterizations may be constrained in most hydrological models. Thus, reconsideration of the river network routing algorithm, better channel hydraulic geometry, a revised $\beta$ factor, and representation of floodplains may be warranted to improve the flood prediction skill.

\section{c. Other factors influencing regional-scale flood prediction skill}

To better understand flood prediction skill at the regional scale, we summarize the NSE statistics in the boxplots using different criteria (Fig. 9). The same analyses are also conducted for the October event (Fig. S3), but only the May event boxplots are presented for simplicity because the general conclusions are similar. Figure 9a shows the regional median NSE is highest for ST4 and Q3GC $(>0.3)$, which agrees with the assessment that ST4 and Q3GC are equally good QPE inputs for the May event. Similarly, Q3GC and Q3RAD have the highest median NSE in the October event based on the best performing 20 gauges (Fig. S1a), matching the rainfall assessment that MRMS QPEs generally outperform ST4 in the October event. Interestingly, the skill interquartile range for MRMS is always narrower than that for ST4 in both events, 


\section{May: 1200 UTC 23 May-1200 UTC 25 May}

(a) ST4

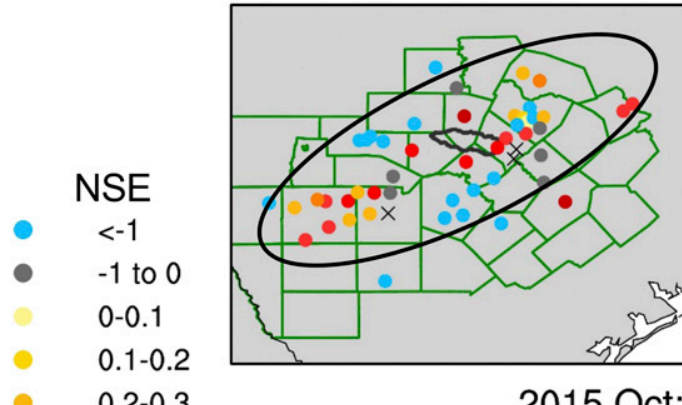

$0.2-0.3$

$0.3-0.4$

$0.4-0.6$

$0.6-0.8$

$>0.8$ (b) Q3GC

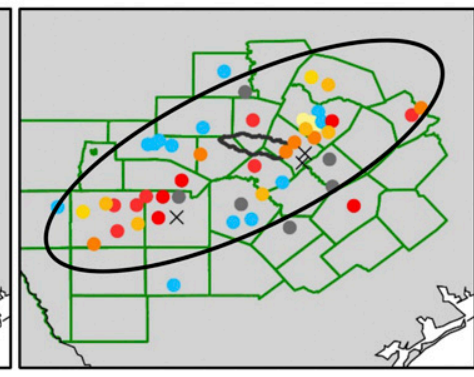

(c) Q3RAD

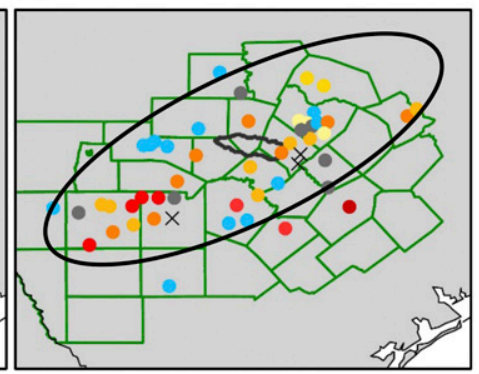

2015 Oct: 0000 UTC 30 Oct-0000 UTC 01 Nov

(d) ST4

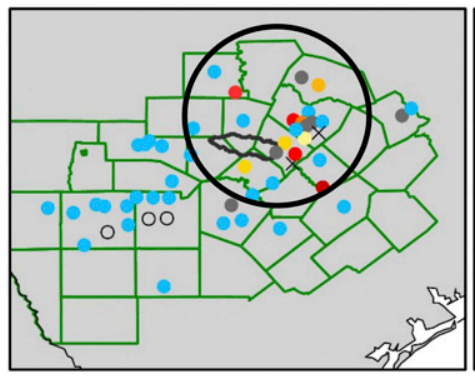

(e) Q3GC

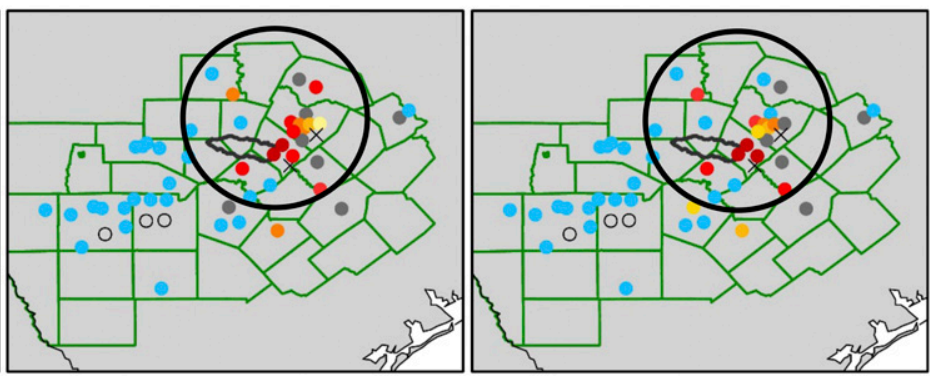

FIG. 8. Regional flood prediction skill for the (a)-(c) May and (d)-(f) October events. The NSEs at 51 gauges are shown. Crosses denote gauges with $>60 \%$ missing measurements; hollow circles denote gauges with zero observed discharge. Black ellipses outline the approximate envelope areas for the storm cells.

indicating that compared to MRMS, ST4 has more variable flood prediction skill across different sites. This range in flood prediction summarizes streamflow simulation uncertainties across a large spatial domain, and variations in quality control performed by RFC hydrologists may help explain why ST4 struggles to generate more regionally consistent skill relative to the automated MRMS product.

The model skill for nonforecasting points is separately shown in Fig. 9b, which is comparable to that of all gauges (see similar median NSE in Fig. 9a). Current NWS operations have an average modeling basin size of $1200 \mathrm{~km}^{2}$ (Kitzmiller et al. 2013), which is reduced to $2-3 \mathrm{~km}^{2}$ after introducing NHDPlus with the NWM to increase the forecast density by a factor of 700 (Lin et al. 2017). The results here suggest that at least for our study domain in south-central Texas, the NWM can retain reasonably good prediction skill for gauges that are not currently the NWS AHPS forecasting points. We also further separate the gauges into referenced (Fig. 9c) and nonreferenced (Fig. 9d) gauges, where much lower skill for the latter group is seen. Nonreferenced gauges mark watersheds with human-altered flows from water management and diversions. Although our evaluation has already excluded gauges downstream of reservoirs, this analysis suggests the model still suffers from other human alterations not yet accounted for. Note that the operational NWM incorporates a simple nudging-based data assimilation (DA) scheme to assimilate observed streamflow at $\sim 7000$ USGS gauges in its historical runs (Table 1), which might help alleviate the problem present in Fig. 9d because human-altered flows could be reflected in the assimilated discharge observations. Additional refinements of the DA capabilities and/or developments of advanced modules are also needed, but it is not expected to resolve the flashiness problem discussed in section $4 \mathrm{~b}$.

Figure 10 examines flood prediction skill by separating the gauges into groups with smaller (yellow) and larger (blue) drainage areas. Most prominently, MRMS QPEs demonstrate the most unique contributions to gauges with smaller drainage areas (especially those under $250 \mathrm{~km}^{2}$ ). Note that the MRMS QPEs are generally less accurate than ST4 during the May event (cf. Figs. 5 and 6), but MRMS prominently outperforms ST4 for smaller drainage basin gauges (Fig. 10). This is most likely because ST4 cannot adequately capture the finescale rainfall patterns as limited by its coarser spatial resolution at $4 \mathrm{~km}$ (median NSE $<0$, blue box plot in Fig. 10a). The same conclusion holds for the October event (see Fig. S1b) in which MRMS already exhibits 
(a) All Gauges [43]

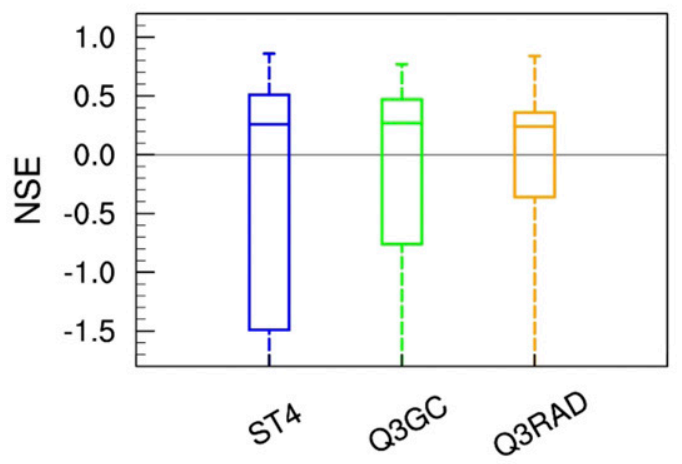

(c) Referenced Gauges [18]

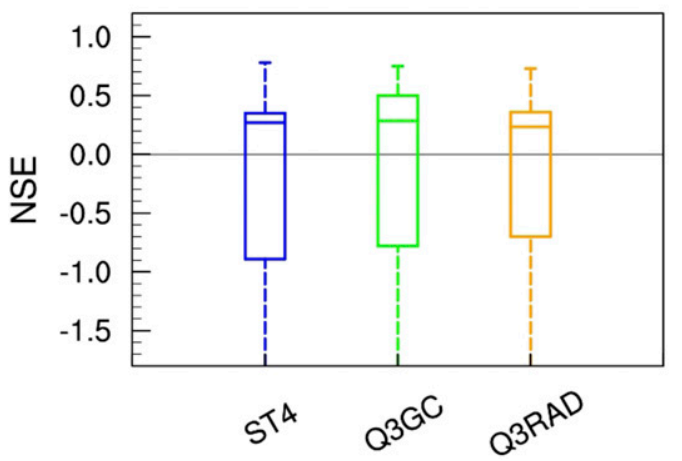

(b) Non-Forecasting Point [21]

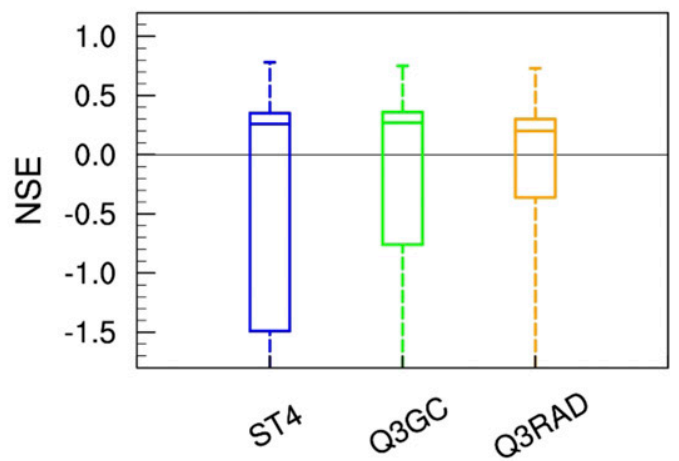

(d) Non-Referenced Gauges [25]

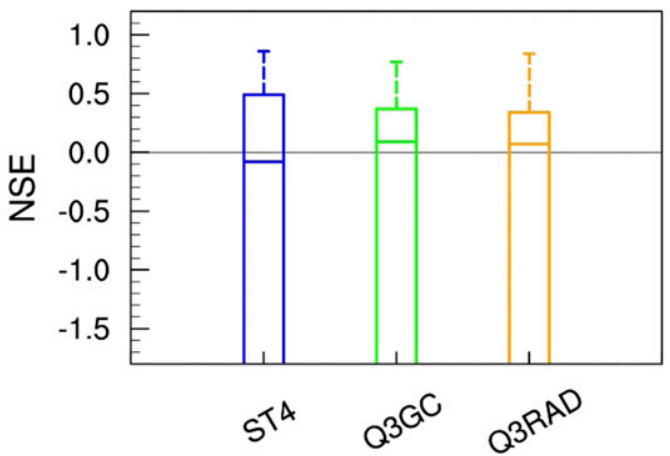

FIG. 9. Boxplots for regional flood prediction skill separated based on different gauge types. Whiskers show the maximum, 75th, median, 25th, and minimum NSE values for the May event (not all minimum values are displayed in the plot). Gauges with $>60 \%$ missing measurements and five gauges with consistent low NSEs $(<-30)$ are excluded; the gauge number used to calculate the statistics is shown in brackets.

better accuracy than ST4. In this event, the degree to which MRMS outperforms ST4 is also more obviously seen for gauges with drainage areas less than $320 \mathrm{~km}^{2}$.

\section{d. Flood hydrographs for selected local gauges of high strategic concerns}

Flood hydrographs are shown in this section (Figs. 11, 12) to provide a more direct assessment on the local-scale flood prediction skill. Six river gauges with high flood impacts and reasonable model performance are shown for both events. Consistent with our regional evaluation, precipitation forcing uncertainty serves as the dominant factor for the overall hydrograph and the peak magnitude prediction, matching the rainfall assessment that ST4 and Q3GC exhibit the best and comparable accuracy in the May event, whereas MRMS outperforms ST4 for the October event. In addition, gauges with smaller drainage areas tend to benefit more from the MRMS QPEs, such as Hondo Creek $\left(249.1 \mathrm{~km}^{2}\right)$, Shoal Creek $\left(32.96 \mathrm{~km}^{2}\right)$, Slaughter Creek $\left(22.72 \mathrm{~km}^{2}\right)$, and Walnut Creek $\left(134.59 \mathrm{~km}^{2}\right)$, especially for the October event in Fig. 12. In comparison, the MRMS QPEs underestimation for the May event (Fig. 6) leads to underestimated peak discharges despite the fact that ST4 has a coarser intrinsic resolution for smaller watersheds (Fig. 11). For both events, the simulated peak timing is $\pm 2 \mathrm{~h}$ around the observed (Fig. S1), and the rising limbs are captured better than the falling limbs. This is particularly important for effective flood warnings, because accurately capturing the crest timing and the rising limbs is the most important factor in emergency management decisions even though NSEs can be lowered down by the imperfect falling limb simulations. For the May event, the predicted flood recessions are faster than observed, which may be a similar model behavior related to the "flashy hydrograph" problem with the current model parameterization (see discussions in section $4 b$ ). Both the regional and local evaluations suggest the channel routing may be oversensitive to changes in the flow velocity and wave celerity. This may have led to good model skill at gauges experiencing rapidly rising and falling floods, while showing unsatisfactory skill over regions without direct flood response; this problem will need to be revisited in future model development efforts. 
(a)

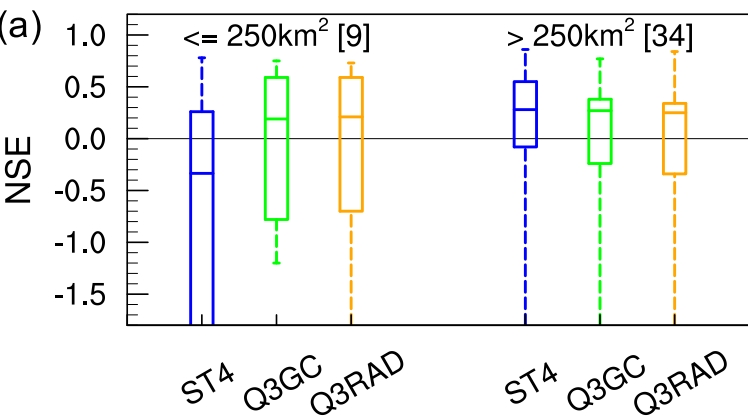

(c)
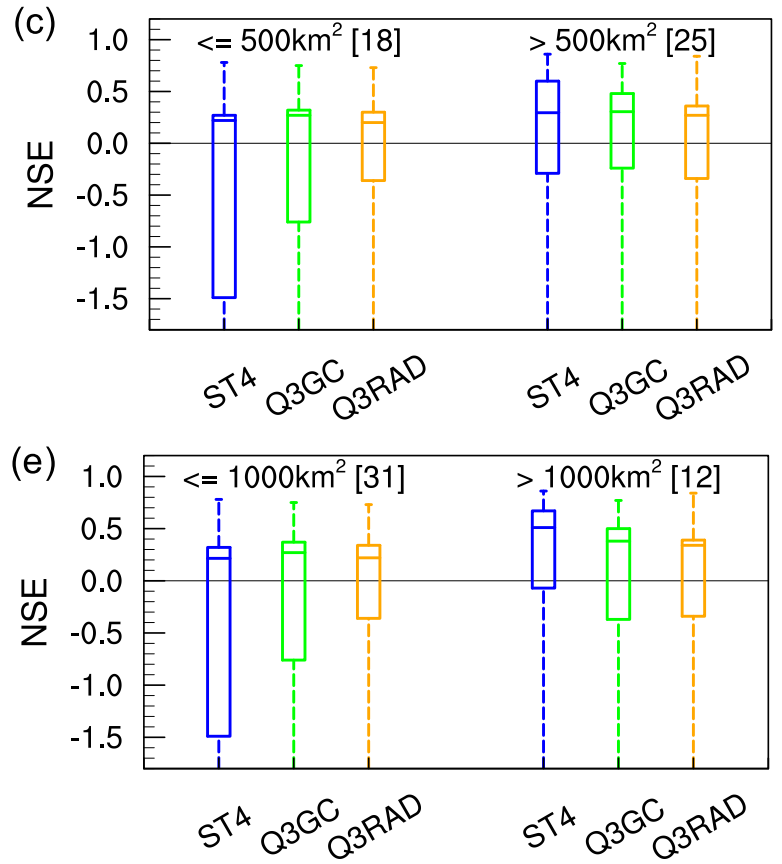

(b)

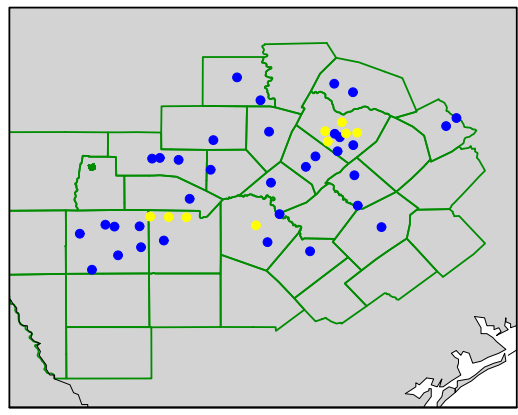

(d)

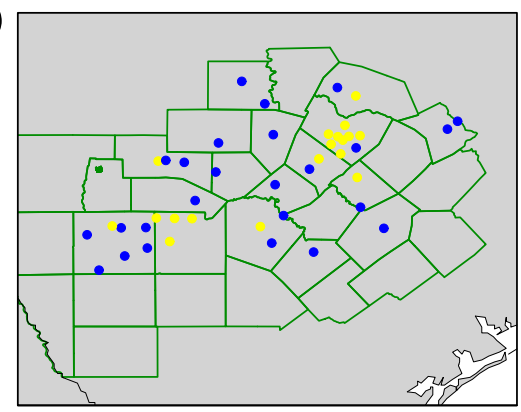

(f)

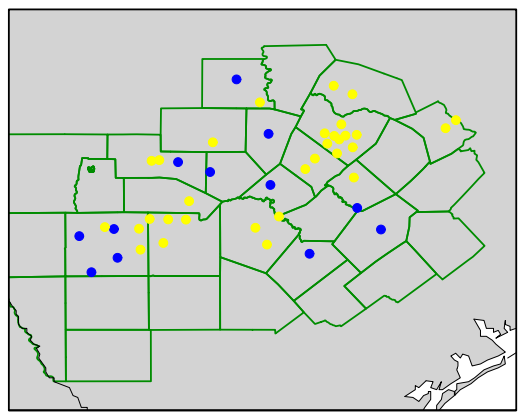

FIG. 10. Boxplots for regional flood prediction skill based on the drainage basin sizes: (a),(c),(e) NSE box plot and (b),(d),(f) the gauge locations within the smaller- (yellow) and larger-area (blue) categories. Whiskers show the maximum, 75th, median, 25th, and minimum NSE values for the May event (not all minimum values are displayed in the plot). Gauges with $>60 \%$ missing measurements and five gauges with consistent low NSEs $(<-30)$ are excluded; the gauge number used to calculate the statistics is shown in brackets.

Although the model performance displayed here is arguably imperfect, it exceeds the expected skill of current NWS AHPS operational capabilities for southcentral Texas, even though the model is not calibrated or tuned against certain events or precipitation forcing. Therefore, these results show promise for enhanced hydrological forecast capability with the NWM, in line with the goals of Braud et al. (2010) for a "model everywhere" that runs for gauged and ungauged basins. However, we also identified several areas that need to be revisited in future studies to improve regional flood prediction skill, which includes dealing with the precipitation uncertainties and spatial resolutions (section 4a), addressing the issue with the model flashiness over regions without an imminent flood response (section $4 \mathrm{~b}$ ), and incorporating modules or DA capabilities to represent human alterations on flows (section $4 \mathrm{c}$ ).

\section{Hydrometeorological drivers for the record flood for Blanco River at Wimberley}

\section{a. Contrasting flood responses for the May and} October 2015 events

Considering the minimally calibrated model performs well at some gauges with NSEs greater than 0.8 , the bestsimulated model results can be used to obtain a better mechanistic understanding of drivers and flood responses at certain locations. In this section, we analyze both events at the Blanco River at Wimberley (USGS 08171000; WMBT2), whose peak flood stage in the May 

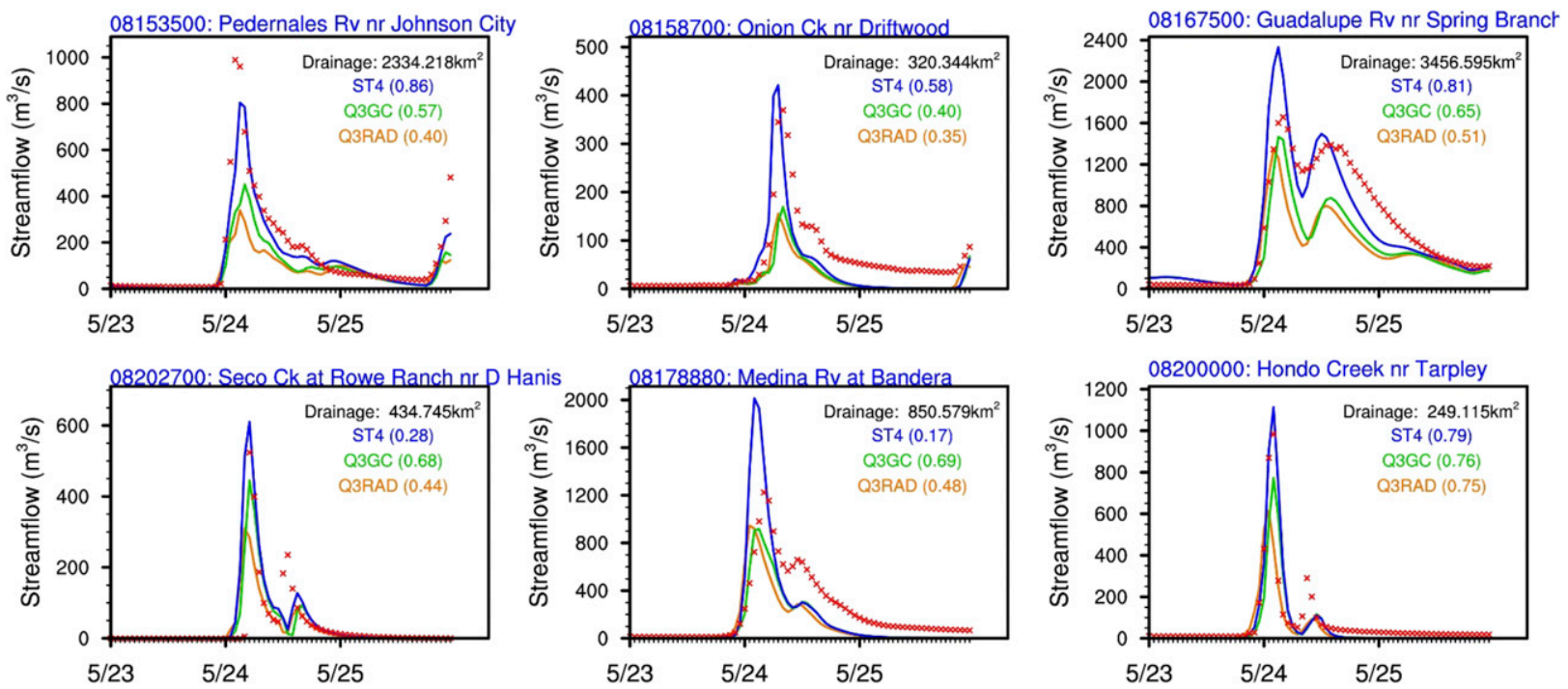

FIG. 11. Flood discharge hydrographs at six gauges of high strategic concerns in the May event. Red crosses stand for USGS observations, and numbers in the parentheses show the NSE values for each experiment (blue, ST4; green, Q3GC; orange, Q3RAD).

event $(13.7 \mathrm{~m})$ exceeded the previous record by $3.5 \mathrm{~m}$. Because of similarities in meteorological characteristics and antecedent soil moisture in both events, the May record flood at WMBT2 that exceeded the October crest by $5.6 \mathrm{~m}$ was difficult to resolve. Therefore, an analysis to understand the complex nature of the May 2015 event at WMBT2 is needed.

Figure 13 shows that the two events observed similar event total precipitation, initial surface soil moisture, and average surface runoff in the drainage basin of WMBT2, yet the spatial distribution is concentrated at different locations. During the May event, most of the heaviest rainfall $(>250 \mathrm{~mm})$ fell on the basin's southwestern part, whereas the October event had slightly heavier rainfall $(>320 \mathrm{~mm}$ ) close to the basin outlet (see the basin river network and terrain in Fig. 15b, and the basin's relative location in central Texas in Figs. 6-8). Antecedent soil moisture conditions were very saturated prior to both events $\left(>0.3 \mathrm{~m}^{3} \mathrm{~m}^{-3}\right.$; Fig. 13b) -one after the wettest April and May for Texas (Furl et al. 2018) and one after receiving $\sim 150 \mathrm{~mm}$ of rainfall associated with the remnants of Hurricane Patricia on
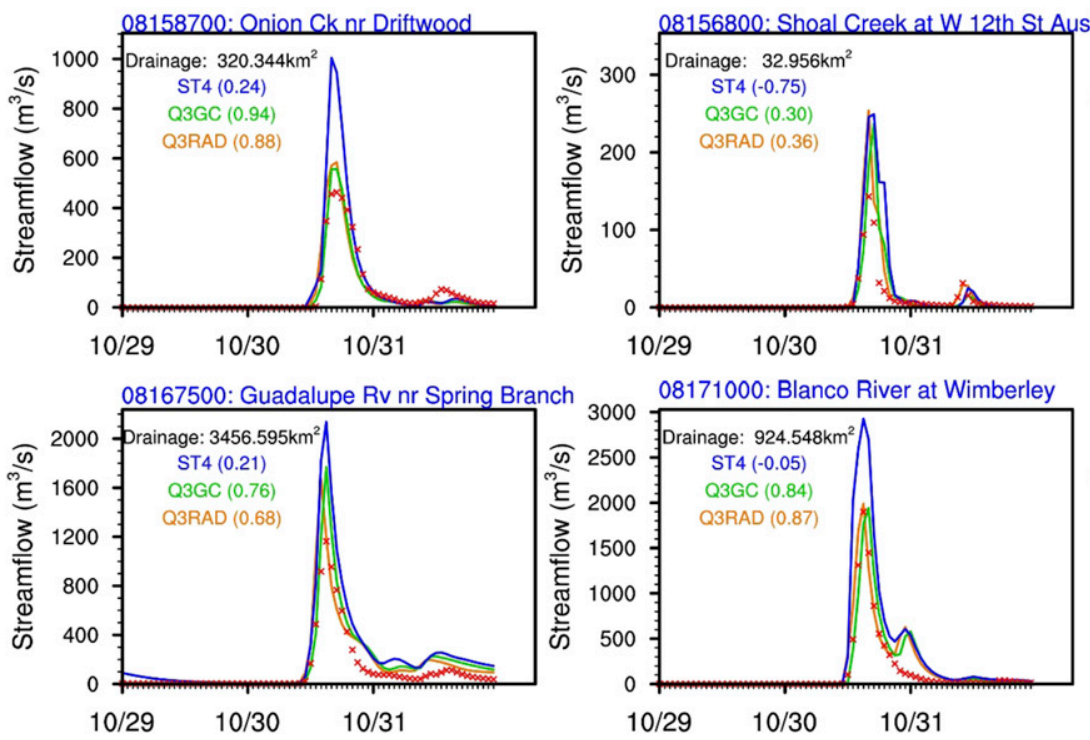

FIG. 12. As in Fig. 11, but for the October event
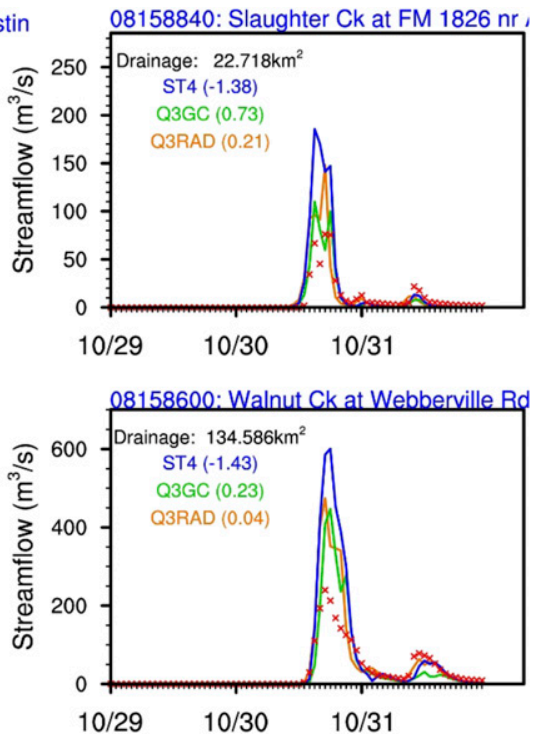
(a) Precipitation $(\mathrm{mm})$

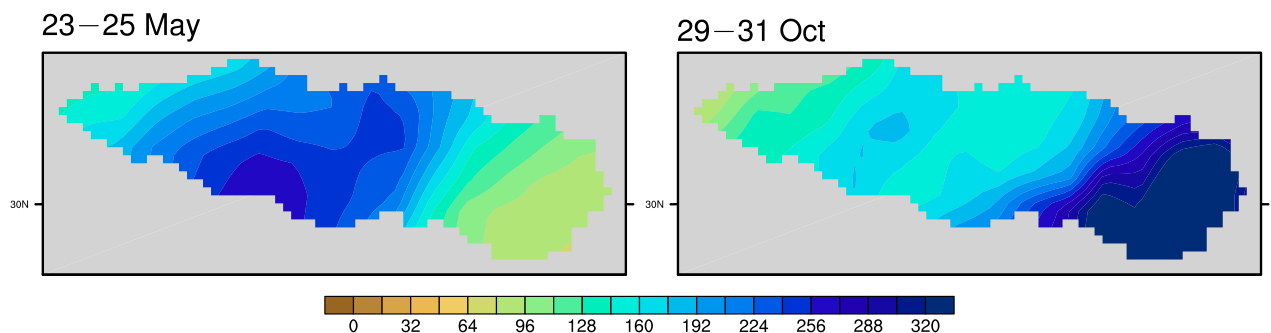

(b) Initial soil moisture $\left(\mathrm{m}^{3} \mathrm{~m}^{-3}\right)$

1200 UTC 22 May

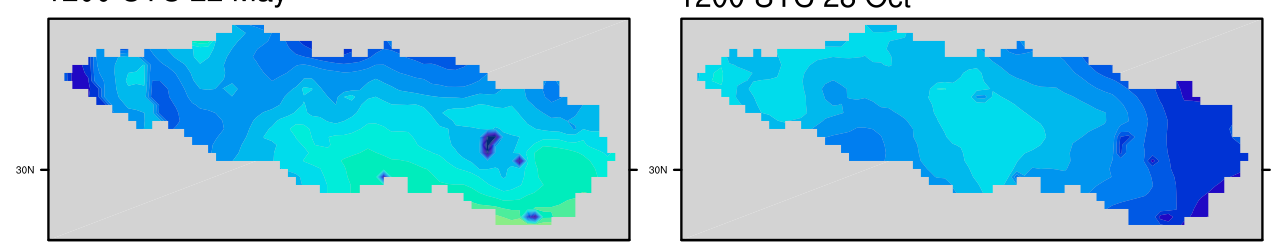

(c) Surface runoff $(\mathrm{mm})$

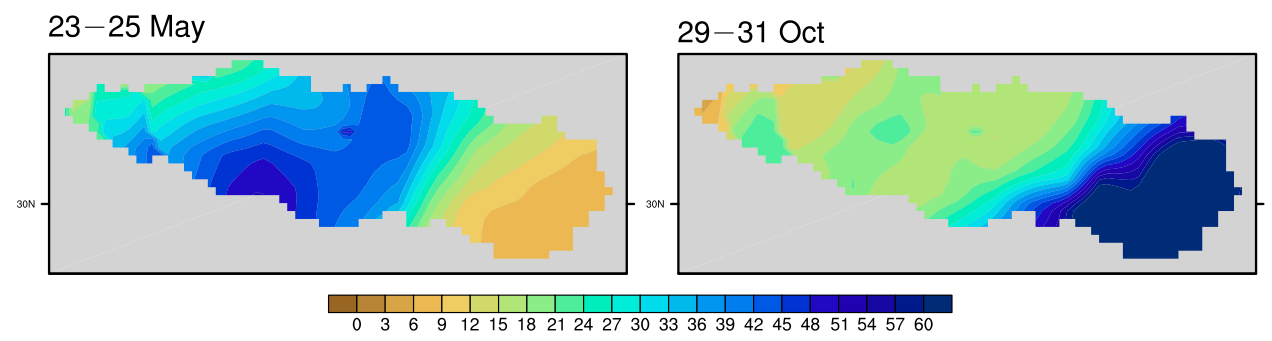

FIG. 13. Hydrometeorological conditions for the drainage basin of WMBT2 during the May and October floods (ST4 for May; Q3RAD for October): (a) the event total precipitation ( $\mathrm{mm}$ ), (b) the initial soil moisture conditions $\left(\mathrm{m}^{3} \mathrm{~m}^{-3}\right)$, and $(\mathrm{c})$ the event-averaged surface runoff $(\mathrm{mm})$. The cycle starts and ends at 1200 UTC of the first and the last day, respectively.

23-24 October 2015 (Rogers et al. 2017). Accordingly, higher surface runoff covering a slightly smaller basin area was generated closer to the basin outlet (Fig. 13c) during the October event relative to the May event.

Interestingly, the observed flood in May had a return period well in excess of 100 years (USGS PeakFQ Flood Frequency Analysis; Veilleux et al. 2014), whereas the October event only reached a 10-yr return period level (see red dots in Fig. 14); the two crests differed by $\sim 40 \%$. The rising limb of the May event was much steeper where the stage increased by nearly $9 \mathrm{~m}$ over a 2 -h interval (0330-0530 UTC on 24 May) to surpass the record. However, the best simulated modeling results forced by ST4 (NSE $=0.68$ ) for the May event and Q3RAD $(\mathrm{NSE}=0.87)$ for the October event were only able to produce slightly different flood responses, with better model simulation for the October event (see blue lines in Fig. 14). A basin-average analysis shows that the rainfall totals only differed by $\sim 20 \%$, and most of the rain for both events precipitated during a same 8-10-h time window (Figs. 15a,b), suggesting that the rainfall total and intensity/duration difference is not enough to explain the two events' difference. It is therefore interesting to examine what other factors may have contributed to the contrasting flood responses and why the model struggles to capture the full magnitude of the May flood peak.

Figure $15 \mathrm{c}$ displays the WMBT2 drainage basin physiographic features and the events' rainfall locations. The upstream headwater catchments over which most of the May event's rain fell feature steep channel bed slopes ( $>0.01$ in Fig. 15c) and relatively straight channels with little sinuosity, which likely led to fast-propagating flood waves that are less easily attenuated along with the eastward propagating rainfall to WMBT2. In comparison, the October event mainly operated on the less steep, more sinuous, and wider downstream portions of the Blanco River, which naturally served to suppress larger flood waves. Note that the flow length to WMBT2 is longer in the May event than in the October event, which Mei et al. (2014) and Zoccatelli et al. (2011) suggest has a 
(a) May Event

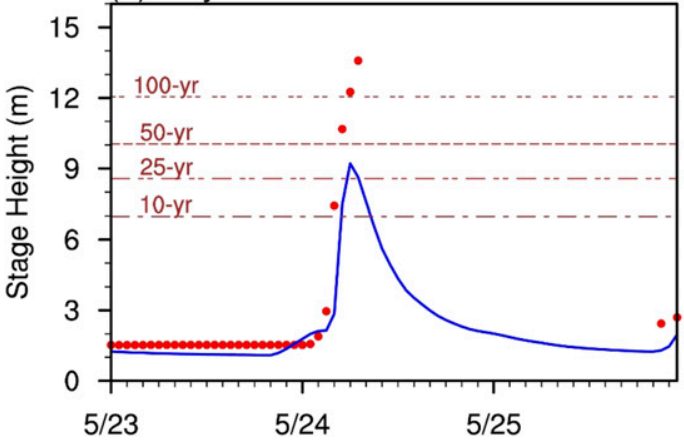

(b) Oct Event

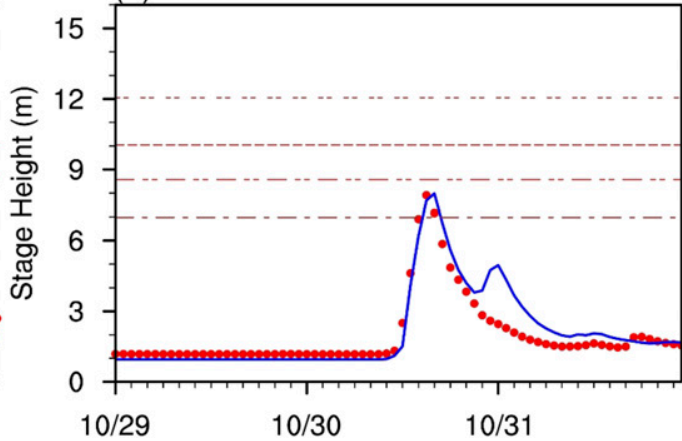

FIG. 14. Flood stage height at WMBT2 during the (a) May and (b) October events in UTC time. Red dots denote observations, and blue lines denote the best-simulated results (ST4 for May; Q3RAD for Oct). Discharge is converted to stage height using the USGS rating curve at WMBT2. Flood return period (dashed lines) is determined using the USGS PeakFQ flood frequency analysis with the annual maximum streamflow excluding the two examined events.

greater effect on delaying the response time of the peak flood wave than on its magnitude. However, in agreement with assertions made in both aforementioned studies, the greater observed peak in the May event suggests that the basin topographic features, the distribution of rainfall within the basin (both spatially and temporally), and the spatial variability of routing and hillslope flow velocities may sometimes be more important than the flow length effects. Further evaluation of the simulation results (blue line in Fig. 14a) suggest the model is able to capture (a)

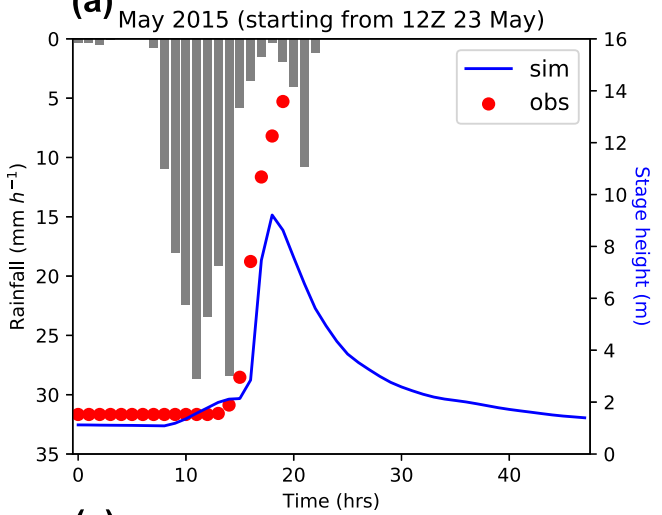

(b)

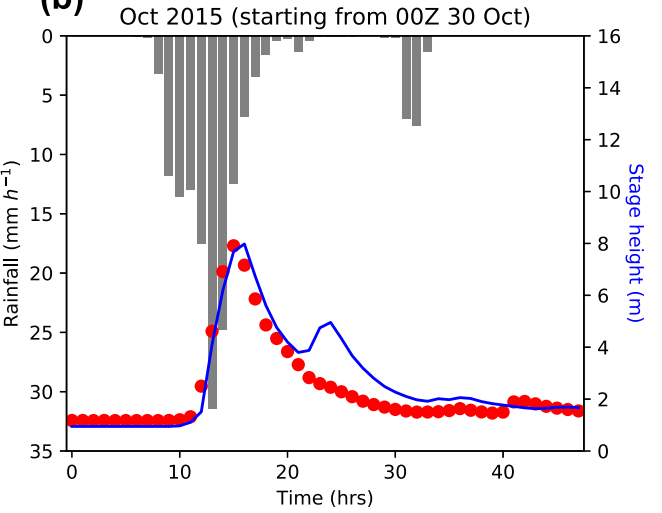

(c)

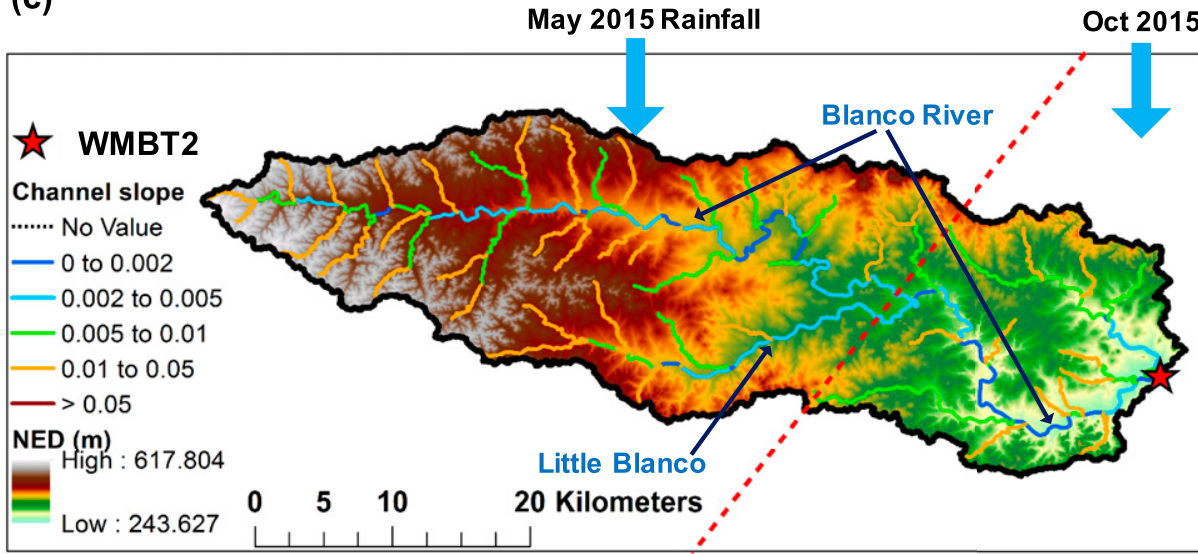

FIG. 15. Hourly rainfall intensity $\left(\mathrm{mm} \mathrm{h}^{-1}\right)$ and stage height $(\mathrm{m})$ for the (a) May and (b) October 2015 events. (c) The basin physiographic features (topography and channel slope). The red dashed line separates the approximate rainfall locations for the two events. 
these differences but only to some degree, with a slightly steeper and higher flood peak simulated for the May event exceeding the 25 -yr return period. This is because the major land physiographic features (e.g., channel and catchment slope) are incorporated in the model's parameterization. However, there is still a significant underestimation of the peak stage for the May record flood, so a quantitative understanding was facilitated through model sensitivity tests combined with the best observational constraints (section 5b).

\section{b. Sensitivity analyses for quantitative understanding of the May 2015 record flood}

Several error sources may cause the underestimation of the peak stage. First, the underestimation may be associated with errors in precipitation forcing, the Noah-MP soil moisture calculation, and the flow velocity calculation with the routing model. Second, measurement errors may also exist with indirect discharge estimations and the rating curve utilized. Third, there may be errors in neglecting flowing debris objects that may obstruct flow at narrower portions of the river channels, increasing viscosity and slowing down flood wave propagation, processes that are not understood well enough to be included in our current modeling framework. Complex surface-subsurface interactions with karstic spring features in south-central Texas may be other factors currently not accounted for (Looper and Vieux 2012), but based on limited observations at a main karstic spring on the Blanco River above WMBT2 (not shown), the spring contributions may play a minor role as they are several orders of magnitude lower than that from surface runoff during big flood events.

Below, precipitation forcing, soil moisture, and flow velocity are examined individually in an attempt to shed light on how they play a role in reproducing the record flood peak in May 2015, rather than attempting to reproduce the full peak magnitude.

1) The most accurate ST4 precipitation for this event is $14.6 \%$ higher than gauged rainfall based on 15 CoCoRaHS and COOP rain gauges in the WMBT2 basin (not shown). This suggests QPE uncertainties alone cannot explain the underpredicted peak stage height.

2) For soil moisture, the model predicts a $\sim 80 \%$ basinaverage degree of saturation for the surface soil layer (see Fig. 13b, based on the dominant soil type of clay loam and maximum soil moisture of $0.465 \mathrm{~m}^{3} \mathrm{~m}^{-3}$ ). Because the basin has an average soil depth of 30$60 \mathrm{~cm}$, sensitivity tests are conducted by saturating the top two soil layers (scenario a: $0-10 \mathrm{~cm}$, scenario b: $0-10 \mathrm{~cm}$ and $10-40 \mathrm{~cm}$ ) in the model's initialization based on each grid cell's soil type. It is found that scenario a and scenario $b$ increase the peak stage height by 0.1 and $1.4 \mathrm{~m}$, respectively, the latter of which at least exceeds the 1929 record flood (Fig. 16). These sensitivity tests agree with previous studies, suggesting the degree of saturation for deeper soils, compared to the surface soil, may play a more important role in the streamflow and peak stage prediction (Rajib et al. 2016) due to its larger water storage.

3) For flow velocity, the only reference data are indirect estimations made by the Guadalupe-Blanco River Authority (GBRA) and some postevent measurements by the USGS (see acknowledgments). According to the May event flow animation (see the online supplemental material), the flood wave propagating down from the Blanco River lagged behind that from the Little Blanco River by $\sim 1 \mathrm{~h}$. To test what the flood responses would be if the two flood waves arrived at the confluence of the Blanco River and the Little Blanco River simultaneously, we manually increased the flow velocity by multiplying the model-predicted velocity by a factor of 1.2 for the first and second Strahler order streams above the conjunction (see Fig. S4 for the order 1 and order 2 Blanco River reaches). Aside from joining the two waves simultaneously in this sensitivity experiment (scenario c), all other conditions are the same as scenario $b$. The peak stage for scenario $\mathrm{c}$ is further increased by another $0.9 \mathrm{~m}$ above scenario $\mathrm{b}$, demonstrating the flow velocity spatial combination may also have played an important role in producing the record flood peak. The flood wave crest in scenario $\mathrm{c}$ is $1-2 \mathrm{~h}$ earlier than observed, which may be explained by debris flows on the sinuous Blanco River that might have temporarily slowed down the flood wave. Nevertheless, increasing the flood peak stage by simply modifying the flow velocity for lowerorder streams $\sim 20 \mathrm{~km}$ upstream suggests accurately representing flow velocity, particularly at the headwaters (McDonnell and Beven 2014), is indeed critical for predicting the May 2015 record flood peak.

Figure 16 also shows that scenario c generally has the closest-to-observed flow velocities at two time pointsone around the crest timing and one during the recession stage (blue arrows). This further confirms the crucial role of initial wetness in deeper soils and flow velocity at headwater catchments, as tested by scenario c, in producing skillful flood peak prediction. The May 2015 record flood at WMBT2 by nature involves more complex spatiotemporal variations in the network's velocity field than the October event, posing more challenges for the model to predict the peak stage height well. Our results indicate a certain spatial combination of the velocity field in the river network may have contributed to the catastrophic record flood in May 2015, and hydrological 


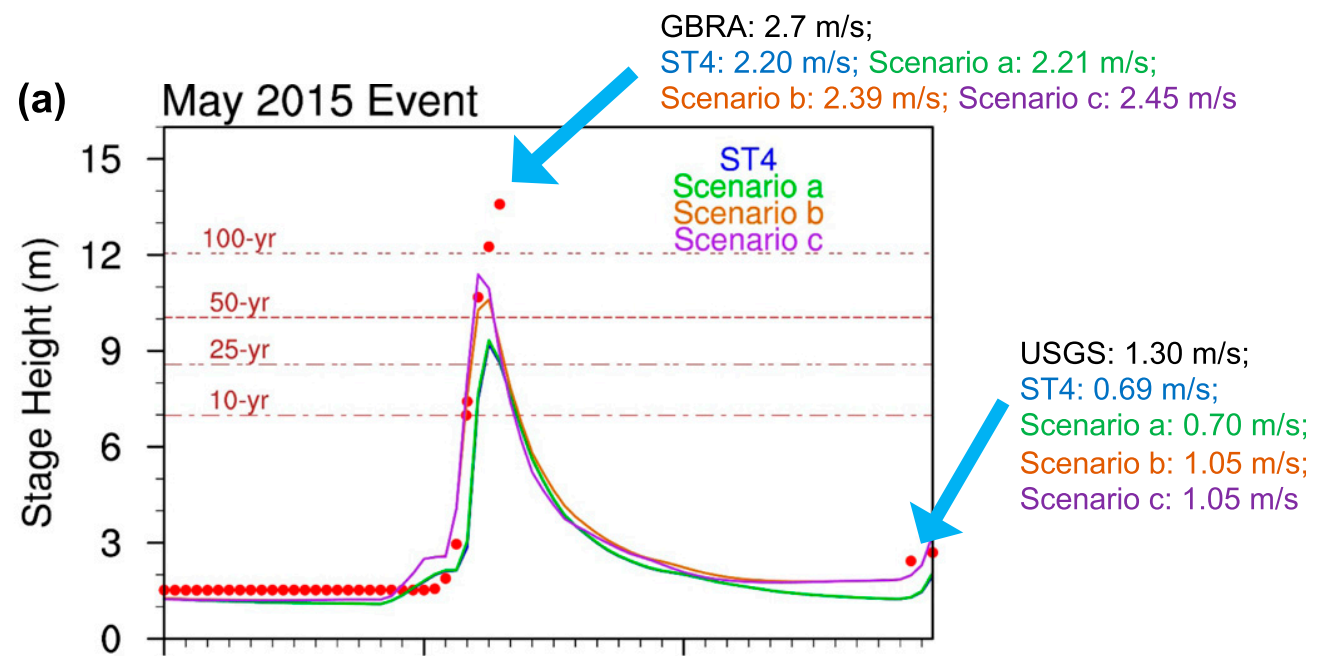

(b) ST4 Control Simulation

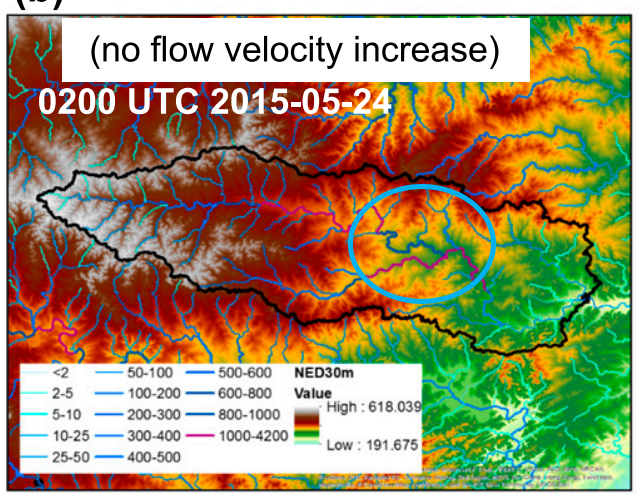

$5 / 25$

(c) Scenario c Simulation

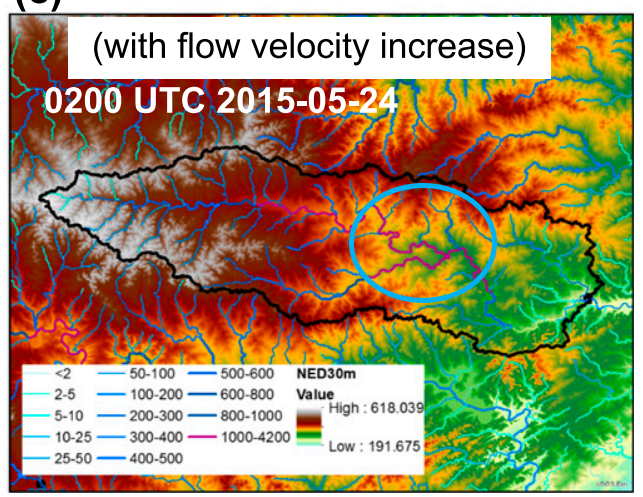

FIG. 16. Stage height (m) for the May 2015 WMBT2 flood simulation sensitivity test scenario a (0-10-cm subsurface layer saturated), scenario b (0-10- and 10-40-cm subsurface layers both saturated), and scenario c (as in scenario b, but multiplying model-predicted velocities on the Blanco River above its confluence with the Little Blanco by 1.2 for all first and second Strahler order streams). Red dots denote observations, and colored lines denote results from different experiments. Blue arrows point to two time points where the model-predicted flow velocities are compared with those estimated by the GBRA and the USGS. Differences in simulated streamflow $\left(\mathrm{m}^{3} \mathrm{~s}^{-1}\right)$ at 0200 UTC 24 May 2015 across the WMBT2 catchment basin are shown in (b) ST4 control and (c) scenario c simulations, with the circled area depicting a faster-moving flood wave simulated by scenario $\mathrm{c}$ at and above the confluence of the (southern stem) Little Blanco with the (northern mainstem) Blanco River.

models need to represent the spatial combination well enough to be able to predict such a flood. Studies evaluating future flood events in the WMBT2 basin will benefit from four additional river gauge measurements that have been installed since 2015, which could improve our mechanistic understanding toward the precipitation drivers, flood responses, and the model prediction skill in the future.

\section{Conclusions and discussion}

This study aims to evaluate how a continental-scale water dynamics model linking meteorology, land surface hydrology, and river channel routing performs in the Texas Hill Country, a well-known flooding hotspot of the United States. Toward this goal, we employ a physically based model configured to resemble the NWM to provide necessary information that may aid NWS forecasters in flood emergency response. Based on two high-impact flood events in the Hill Country during May and October 2015, comprehensive assessments are conducted using the best observational constraints (i.e., 947 daily rain gauges, 138 hourly rain gauges, and 51 USGS river gauges) to identify the model's strengths and weaknesses. Major conclusions of the regional-scale model evaluation are summarized below. 
- Using two radar-based QPE products (i.e., ST4 and MRMS), we found the minimally calibrated flood prediction skill generally follows the event precipitation accuracy from the evaluation at a range of gauges. This highlights the critical role of precipitation forcing inputs in accurate flood prediction at the regional scale.

- Because of the increased spatial resolution, MRMS clearly outperforms ST4, particularly in gauged basins with small drainage areas with room left for improvement for its automated algorithm.

- Overall, the model not only shows good performance at gauges experiencing rapid rises of floodwater from causative rainfall, but also performs reasonably well for gauges that currently are not NWS AHPS forecast points. These results show great promise for enhanced hydrologic forecasting capability for emergency response.

- However, the model suffers from poor prediction skill at gauges with less rapid flood responses and those with human-altered flows, suggesting the need for revised channel routing algorithms and explicit considerations for human alterations.

Note that the current NWM implements a simple levelpool routing for 1260 major man-made reservoirs and initial DA capabilities, which may help alleviate problems with human-altered flows. However, the results pointing to the channel routing are applicable to the NWM and similar model configurations using the same MC routing and channel parameters. In future studies, more advanced channel routing considering floodplain representations and reservoir operations, combined with refined DA algorithms, and terrain-based routing under continuing development of the NWM need to be explicitly tested in order to quantify how the inclusion of these modules could improve the regional model performance.

In addition to model evaluation, this study also probes into the hydrometeorological factors contributing to the contrasting flood responses at WMBT2 in May and October 2015. This investigation is to facilitate mechanistic understanding on the basin's unexpected flood response in May 2015 and to dig further into reasons on why the model struggles with predicting the record flood. Conclusions from this local assessment are listed below.

- Using the best-simulated results, it is shown the location of the intense rainfall in combination with the land physiographic features are the key factors that may help partly explain the two events' different flood responses.

- By conducting a series of model sensitivity tests, we demonstrate the record flood peak in May 2015 can be better obtained by tuning the deeper soil initial wetness and the flow velocity field in the river network. This clearly highlights the crucial role of subsurface soil saturation and the network's flow velocity in producing an unexpected flood response at WMBT2.

These model sensitivity tests not only offer insights into the causes and the complex nature of the local record flood in May 2015, but also help point to possible reasons why the model struggles to predict the flood peak. Other factors that are not incorporated either in the current modeling framework or the NWM may also play a role, such as subsurface contributions from karstic springs and debris flows that may pile up flood water at certain locations along the river. Because of a lack of observations, however, our current understanding and modeling capabilities for these processes are still limited, and thus their targeted observations are warranted in the future.

Acknowledgments. This study is supported by the UCAR COMET NWS Partners Project (Award Z16-23463). David R. Maidment and Xing Zheng from UT-Austin are thanked for offering project suggestions. Jian Zhang and the MRMS group are acknowledged for their helpful discussions. Special thanks go to David J. Gochis (NCAR), Youcun Qi (NOAA), Arezoo Rafieei Nasab (NCAR), and Alec MacDonald (USGS) for helping with the NWM, MRMS, HADS, and river discharge/velocity data during gauge failure. Other datasets are downloaded from publicly available sites, including ST4 (https://data.eol.ucar.edu/dataset/21.093), MRMS QPE (http://mtarchive.geol.iastate.edu/2015/), Global Historical Climatology Network gauged precipitation (ftp://ftp.ncdc.noaa.gov/pub/data/ghcn/daily/), and USGS quality-controlled discharge (https://waterdata. usgs.gov/nwis). We also thank three anonymous reviewers and the editor for their suggestions to improve the quality of the manuscript. The model codes and simulations for this study are available upon request to the corresponding author. The authors declare no conflicts of interest.

\section{APPENDIX}

\section{Model Augmentation Details}

\section{a. Time-variant overland flow delay}

At each LSM time step $i$, surface and subsurface runoff generated on Noah-MP grid cells are averaged based on intersected areas with NHDPlus catchments using an area-weighted coupling approach (Lin et al. 2018). This produces lateral inflows $Q_{\text {lateral }}^{i}\left(\mathrm{~m}^{3} \mathrm{~s}^{-1}\right)$ for the "blue line" river reaches, which first travels along NHDPlus catchments as overland flow, and then is routed through river channels. Based on the geospatial attributes of the NHDPlus, overland flow travel time 
$T_{\text {ov }}$ can be computed using Eq. (A1) (Neitsch et al. 2009; Cho and Engel 2017), in which $T_{\mathrm{ov}}$ is a function of the catchment flow length $L_{\text {cat }}$, average catchment slope (slp), catchments' roughness coefficient $n_{\text {cat }}$, and lateral inflows $\left(Q_{\text {lateral }}^{i}\right)$. Equation (A1) thus represents a time-variant form of $T_{\mathrm{ov}}$ that varies with $Q_{\text {lateral }}^{i}$, where higher $Q_{\text {lateral }}^{i}$ can lead to smaller $T_{\mathrm{ov}}$. In the equation, $n_{\text {cat }}$ is the roughness coefficient related to land cover types obtained from the WRF-Hydro lookup table (Gochis et al. 2015); $L_{\text {cat }}(\mathrm{m})$ is approximated as half of the catchment area divided by channel length, similar to $\mathrm{Li}$ et al. (2013); and $\operatorname{slp}\left(\mathrm{m} \mathrm{m}^{-1}\right)$ is derived from terrain analysis in ArcGIS (Fig. 1c):

$$
T_{\text {ov }}=\frac{\left(L_{\text {cat }} n_{\text {cat }}\right)^{0.6}}{\operatorname{slp}^{0.3} Q_{\text {lateral }}^{i}} .
$$

Taking into account the $T_{\text {ov }}$ delay, the lateral inflow that is able to contribute to the vector flowlines $\left(Q_{\text {lateral }, r}^{i}\right)$ is computed using Eqs. (A2) and (A3) (Neitsch et al. 2009), where $S^{i-1}$ and $S^{i}$ are runoff stored in the catchment at the previous and current routing time step, respectively $\left(S^{0}=0\right) ; \alpha$ is the runoff lag coefficient, which is calculated for each catchment using the $T_{\mathrm{ov}}$ equation of Neitsch et al. (2009) assuming an average net incoming flux of $6.35 \mathrm{~mm} \mathrm{~h}^{-1}$; and $f$ is an adjustment factor currently set as 0.5 :

$$
\begin{aligned}
Q_{\text {lateral }, r}^{i} \Delta t & =\left(Q_{\text {lateral }}^{i} \Delta t+S^{i-1}\right)\left(1-e^{-f \alpha / T_{\text {ov }}}\right) \quad \text { and } \\
S^{i} & =Q_{\text {lateral }}^{i} \Delta t+S^{i-1}-Q_{\text {lateral }, r}^{i} \Delta t
\end{aligned}
$$

\section{b. Time-variant channel flow: Augmentation of the $M C$ routing}

After $Q_{\text {lateral }, r}^{i}$ reaches the NHDPlus flowlines, an augmented MC channel routing algorithm is implemented to replace the original RAPID Muskingum routing for two reasons. First, MC is adopted by the operational NWM and results from MC may help better inform strengths and weaknesses of the current NWM. Second, MC is a more physically based method than Muskingum because it uses the channel geometry characteristics and the predicted discharge to update its routing parameters $k$ and $x$ at each time step; thus, it may be more adapted to actual prediction applications where no observed data could be obtained prior to a particular event as required by the Muskingum method.

$\mathrm{MC}$ and Muskingum solve the same Eq. (A4) to predict river reach $j$ 's outflow at time point $i\left(Q_{j}^{i}\right)$, where $C_{1}$, $C_{2}$, and $C_{3}$ are coefficients computed using $k$ and $x$, and $C_{4}$ is a coefficient for lateral inflow contributions [Eqs. (A5)-(A8)]:

$$
\begin{aligned}
Q_{j}^{i} & =C_{1} Q_{j-1}^{i-1}+C_{2} Q_{j-1}^{i}+C_{3} Q_{j}^{i-1}+C_{4}, \\
C_{1} & =(k x+\Delta t / 2) / D, \\
C_{2} & =(\Delta t / 2-k x) / D, \\
C_{3} & =[k(1-x)-\Delta t / 2] / D, \\
C_{4} & =Q_{\text {lateral }, r}^{i} \Delta t / D, \quad \text { and } \\
D & =k(1-x)+\Delta t / 2 .
\end{aligned}
$$

In Muskingum, $k$ and $x$ are constant in time; in MC, $k$ is updated at each time step using the channel length $\Delta L$ divided by the instantaneous wave celerity $c$ and $x$ is updated using peak flow $Q_{p}$, top width (tw), channel bed slope (bs), $\Delta L$ and $c$ [Eqs. (A10) and (A11); Bedient and Huber 1988]:

$$
\begin{aligned}
& k=\Delta L / c \quad \text { and } \\
& x=0.5-Q_{p} /(2 \times \mathrm{tw} \times \text { bs } \times c \Delta L) .
\end{aligned}
$$

Using Manning's equation, the instantaneous wave celerity $c$ is estimated using the river flow velocity $v$; a function of the channel roughness $n_{\text {chan }}$; hydraulic radius (hr); bs [Eq. (A12)]; and $\beta$, a coefficient to relate $c$ with $v$. Coefficient $\beta$ is equal to $5 / 3$ for cross sections where the hydraulic radius can be approximated by the depth, where a more accurate $\beta$ should decrease after exceeding the channel capacity and increase again with deep flow in the floodplain (Merkel 2002). For preliminary use in the initial NWM and this study, a constant $\beta$ of $5 / 3$ is used but future studies need to better represent this factor based on more detailed considerations for the river channel and floodplain hydraulics. At each routing time step, hr is first updated using the Newton-Raphson iterative method that converges when the steady-state $Q_{j}^{i-1}$ are satisfied for the trapezoidal channel shape, after which all parameters are updated using Eqs. (A5)-(A13):

$$
\begin{aligned}
& v=1 / n_{\text {chan }} \times \mathrm{hr}^{2 / 3} \times \mathrm{bs}^{1 / 2} \quad \text { and } \\
& c=\beta v .
\end{aligned}
$$

\section{REFERENCES}

Ashley, S. T., and W. S. Ashley, 2008: Flood fatalities in the United States. J. Appl. Meteor. Climatol., 47, 805-818, https://doi.org/ 10.1175/2007JAMC1611.1.

Bedient, P. P., and W. C. Huber, 1988: Hydrology and Floodplain Analysis. Addison-Wesley, $650 \mathrm{pp}$.

Beven, K., 2006: A manifesto for the equifinality thesis. J. Hydrol., 320, 18-36, https://doi.org/10.1016/j.jhydrol.2005.07.007.

Boucher, O., and Coauthors, 2013: Clouds and aerosols. Climate Change 2013: The Physical Science Basis, T. F. Stocker et al., Eds. Cambridge University Press, 571-657.

Braud, I., H. Roux, S. Anquetin, M. Maubourguet, C. Manus, P. Viallet, and D. Dartus, 2010: The use of distributed 
hydrological models for the Gard 2002 flash flood event: Analysis of associated hydrological processes. J. Hydrol., 394, 162-181, https://doi.org/10.1016/j.jhydrol.2010.03.033.

Cai, X., Z.-L. Yang, C. H. David, G.-Y. Niu, and M. Rodell, 2014: Hydrological evaluation of the Noah-MP land surface model for the Mississippi River Basin. J. Geophys. Res. Atmos., 119, 23-38, https://doi.org/10.1002/2013JD020792.

Cho, Y., and B. A. Engel, 2017: NEXRAD quantitative precipitation estimations for hydrologic simulation using a hybrid hydrologic model. J. Hydrometeor., 18, 25-47, https://doi.org/ 10.1175/JHM-D-16-0013.1.

Cocks, S. B., S. M. Martinaitis, B. Kaney, J. Zhang, and K. Howard, 2016: MRMS QPE performance during the 2013/14 cool season. J. Hydrometeor., 17, 791-810, https://doi.org/10.1175/ JHM-D-15-0095.1.

Corfidi, S. F., J. H. Merritt, and J. M. Fritsch, 1996: Predicting the movement of mesoscale convective complexes. Wea. Forecasting, 11, 41-46, https://doi.org/10.1175/1520-0434(1996) $011<0041$ :PTMOMC $>2.0 . C O ; 2$.

David, C. H., D. R. Maidment, G.-Y. Niu, Z.-L. Yang, F. Habets, and V. Eijkhout, 2011: River network routing on the NHDPlus dataset. J. Hydrometeor., 12, 913-934, https://doi.org/10.1175/ 2011JHM1345.1.

Downton, M. W., J. Z. B. Miller, and R. A. Pielke Jr., 2005: Reanalysis of U.S. National Weather Service flood loss database. Nat. Hazards Rev., 6, 13-22, https://doi.org/10.1061/(ASCE) 1527-6988(2005)6:1(13).

Emanuel, K., 2017: Assessing the present and future probability of Hurricane Harvey's rainfall. Proc. Natl. Acad. Sci. USA, 114, 12 681-12 684, https://doi.org/10.1073/pnas.1716222114.

Furl, C., H. O. Sharif, A. E. Hassan, N. Mazari, D. Burtch, and G. L. Mullendore, 2015: Hydrometeorological analysis of Tropical Storm Hermine and central Texas flash flooding, September 2010. J. Hydrometeor., 16, 2311-2327, https://doi.org/10.1175/ JHM-D-14-0146.1.

—, H. Sharif, J. W. Zeitler, A. E. Hassan, and J. Joseph, 2018: Hydrometeorology of the catastrophic Blanco river flood in South Texas, May 2015. J. Hydrol. Reg. Stud., 15, 90-104, https://doi.org/10.1016/j.ejrh.2017.12.001.

Gochis, D. J., W. Yu, and D. N. Yates, 2015: The WRF-Hydro model technical description and user's guide, version 3.0. NCAR Tech. Doc., 120 pp., http://www.ral.ucar.edu/projects/wrf_hydro/.

Grice, G. K., and R. A. Maddox, 1983: Synoptic characteristics of heavy rainfall events in South Texas. Natl. Wea. Dig., 8, 8-16.

Gupta, H. V., H. Kling, K. K. Yilmaz, and G. F. Martinez, 2009: Decomposition of the mean squared error and NSE performance criteria: Implications for improving hydrological modelling. J. Hydrol., 377, 80-91, https://doi.org/10.1016/ j.jhydrol.2009.08.003.

Hershfield, D. M., 1961: Rainfall frequency atlas of the United States: For durations from 30 minutes to 24 hours and return periods from 1 to 100 years. U.S. Weather Bureau Technical Paper 40, 65 pp., http://www.nws.noaa.gov/oh/hdsc/ PF_documents/TechnicalPaper_No40.pdf.

Hopper, L. J., Jr., and N. L. Hampshire, 2016: Rainfall distributions for varying environmental conditions along the Balcones Escarpment, Texas. 30th Conf. on Hydrology, New Orleans, LA, Amer. Meteor. Soc., 1.3, https://ams.confex.com/ams/ 96Annual/webprogram/Paper281700.html.

Kitzmiller, D., D. Miller, R. Fulton, and F. Ding, 2013: Radar and multisensor precipitation estimation techniques in National Weather Service hydrologic operations. J. Hydrol. Eng., 18, 133142, https://doi.org/10.1061/(ASCE)HE.1943-5584.0000523.
Koster, R. D., Z. Guo, R. Yang, P. A. Dirmeyer, K. Mitchell, and M. J. Puma, 2009: On the nature of soil moisture in land surface models. J. Climate, 22, 4322-4335, https://doi.org/10.1175/ 2009JCLI2832.1.

Leopold, L. B., 1991: Lag times for small drainage basins. Catena, 18, 157-171, https://doi.org/10.1016/0341-8162(91)90014-O.

Li, H., M. S. Wigmosta, H. Wu, M. Huang, Y. Ke, A. M. Coleman, and L. R. Leung, 2013: A physically based runoff routing model for land surface and earth system models. J. Hydrometeor., 14, 808-828, https://doi.org/10.1175/JHM-D-12-015.1.

Lin, P., M. A. Rajib, Z.-L. Yang, M. Somos-Valenzuela, V. Merwade, D. R. Maidment, Y. Wang, and L. Chen, 2017: Spatio-temporal evaluation of simulated evapotranspiration and streamflow over Texas using the WRF-Hydro-RAPID framework. J. Amer. Water Resour. Assoc., 54, 40-54, https:// doi.org/10.1111/1752-1688.12585.

- Z.-L. Yang, D. J. Gochis, W. Yu, D. R. Maidment, M. A. Somos-Valenzuela, and C. H. David, 2018: Implementation of a vector-based river network routing model in the community WRF-Hydro system for flood discharge simulation. Environ. Modell. Software, 107, https://doi.org/10.1016/ j.envsoft.2018.05.018.

Lin, Y., 2011: GCIP/EOP Surface: Precipitation NCEP/EMC 4KM Gridded Data (GRIB) Stage IV Data. Version 1.0, UCAR/ NCAR Earth Observing Laboratory, accessed 5 August 2018, http://data.eol.ucar.edu/dataset/21.093.

Looper, J. P., and B. E. Vieux, 2012: An assessment of distributed flash flood forecasting accuracy using radar and rain gauge input for a physics-based distributed hydrologic model. J. Hydrol., 412-413, 114-132, https://doi.org/10.1016/ j.jhydrol.2011.05.046.

Maddox, R. A., C. F. Chappell, and L. R. Hoxit, 1979: Synoptic and meso- $\alpha$ scale aspects of flash flood events. Bull. Amer. Meteor. Soc., 60, 115-123, https://doi.org/10.1175/1520-0477-60.2.115.

Maidment, D. R., 2016: Conceptual framework for the National Flood Interoperability Experiment. J. Amer. Water Resour. Assoc., 53, 245-257, https://doi.org/10.1111/1752-1688.12474.

McDonnell, J. J., and K. Beven, 2014: Debates-The future of hydrological sciences: A (common) path forward? A call to action aimed at understanding velocities, celerities and residence time distributions of the headwater hydrograph. Water Resour. Res., 50, 5342-5350, https://doi.org/10.1002/2013WR015141.

Mei, Y., E. N. Anagnostou, D. Stampoulis, E. I. Nikolopoulos, M. Borga, and H. J. Vegara, 2014: Rainfall organization control on the flood response of mild-slope basins. J. Hydrol., 510, 565-577, https://doi.org/10.1016/j.jhydrol.2013.12.013.

Merkel, W. H., 2002: Muskingum-Cunge flood routing procedure in NRCS hydrologic models. Second Federal Interagency Hydrologic Modeling Conf., Las Vegas, NV, Advisory Committee on Water Information, 12 pp., https:// www.hydrocad.net/pdf/Merkel-MC-paper.pdf.

Milly, P. C. D., J. Betancourt, M. Falkenmark, R. M. Hirsch, Z. W. Kundzewicz, D. P. Lettenmaier, and R. J. Stouffer, 2008: Stationarity is dead: Whither water management? Science, 319, 573-574, https://doi.org/10.1126/science.1151915.

Neitsch, S. L., J. G. Arnold, J. R. Kiniry, R. Srinivasan, and J. R. Williams, 2009: Soil and water assessment tool theoretical documentation, version 2009. Texas Water Resources Institute Tech. Rep. 406, 618 pp., http://oaktrust.library.tamu.edu/ handle/1969.1/128050.

Niu, G.-Y., and Coauthors, 2011: The community Noah land surface model with multiparameterization options (Noah-MP): 1. Model description and evaluation with local-scale 
measurements. J. Geophys. Res., 116, D12109, https:// doi.org/10.1029/2010JD015139.

NWS, 2015: Exceedance probability analysis for the Central Texas rainfall events of late October 2015. Tech. Doc., 6 pp., ftp://hdsc.nws. noaa.gov/pub/hdsc/data/aep/201510_Texas/AEP_TX_201510.pdf.

_ - 2016a: Weather fatalities 2016. NWS Office of Climate, Water, and Weather Services, http://www.nws.noaa.gov/om/ hazstats.shtml.

_ 2016b: Exceedance probability analysis for the San Antonio Area rainfall event of 23-24 May 2015. Tech. Doc., 5 pp., ftp://hdsc.nws. noaa.gov/pub/hdsc/data/aep/201505_Texas/AEP_TX_201505.pdf.

Pielke, R. A., Jr., M. W. Downton, and J. B. Miller, 2002: Flood damage in the United States, 1926-2000: A reanalysis of National Weather Service estimates. NCAR Doc. 96 pp., http://sciencepolicy.colorado.edu/flooddamagedata/ flooddamagedata.pdf.

Qi, Y., S. Martinaitis, J. Zhang, and S. Cocks, 2016: A real-time automated quality control of hourly rain gauge data based on multiple sensors in MRMS system. J. Hydrometeor., 17, 16751691, https://doi.org/10.1175/JHM-D-15-0188.1.

Rajib, A. M., V. Merwade, and Z. Yu, 2016: Multi-objective calibration of a hydrologic model using spatially distributed remotely sensed/in-situ soil moisture. J. Hydrol., 536, 192-207, https://doi.org/10.1016/j.jhydrol.2016.02.037.

Reges, H. W., N. Doesken, J. Turner, N. Newman, A. Bergantino, and Z. Schwalbe, 2016: CoCoRaHS: The evolution and accomplishments of a volunteer rain gauge network. Bull. Amer. Meteor. Soc., 97, 1831-1846, https://doi.org/10.1175/BAMS-D-14-00213.1.

Rogers, R. F., and Coauthors, 2017: Rewriting the tropical record books: The extraordinary intensification of Hurricane Patricia (2015). Bull. Amer. Meteor. Soc., 98, 2091-2112, https://doi.org/ 10.1175/BAMS-D-16-0039.1.

Saharia, M., P.-E. Kirstetter, H. Vergara, J. J. Gourley, Y. Hong, and M. Giroud, 2017: Mapping flash flood severity in the United States. J. Hydrometeor., 18, 397-411, https://doi.org/ 10.1175/JHM-D-16-0082.1.

Schaake, J. C., V. I. Koren, Q.-Y. Duan, K. Mitchell, and F. Chen, 1996: Simple water balance model for estimating runoff at different spatial and temporal scales. J. Geophys. Res., 101, 7461-7475, https://doi.org/10.1029/95JD02892.

Schroeder, A., J. Basara, J. M. Shepherd, and S. Nelson, 2016: Insights into atmospheric contributors to urban flash flooding across the United States using an analysis of rawinsonde data and associated calculated parameters. J. Appl. Meteor. Climatol., 55, 313-323, https://doi.org/10.1175/JAMC-D-14-0232.1.

Schumacher, R. S., and R. H. Johnson, 2005: Organization and environmental properties of extreme-rain-producing mesoscale convective systems. Mon. Wea. Rev., 133, 961-976, https:// doi.org/10.1175/MWR2899.1.

— convective systems associated with midlevel cyclonic circulations. Wea. Forecasting, 24, 555-574, https://doi.org/10.1175/ 2008WAF2222173.1.
Sharif, H. O., A. A. Hassan, S. Bin-Shafique, H. Xie, and J. Zeitler, 2010: Hydrologic modeling of an extreme flood in the Guadalupe River in Texas. J. Amer. Water Resour. Assoc., 46, 881-891, https://doi.org/10.1111/j.1752-1688.2010.00459.x.

Sivapalan, M., 2018: From engineering hydrology to Earth system science: Milestones in the transformation of hydrologic science. Hydrol. Earth Syst. Sci., 22, 1665-1693, https://doi.org/ 10.5194/hess-22-1665-2018.

Smith, J. A., M. Baeck, J. E. Morrison, and P. Sturdevant-Rees, 2000: Catastrophic rainfall and flooding in Texas. J. Hydrometeor., 1, 5-25, https://doi.org/10.1175/1525-7541(2000)001<0005: CRAFIT $>2.0 . \mathrm{CO} ; 2$.

Smith, M. B., and Coauthors, 2012: Results of the DMIP 2 Oklahoma experiments. J. Hydrol., 418-419, 17-48, https://doi.org/ 10.1016/j.jhydrol.2011.08.056.

Todini, E., 2007: A mass conservative and water storage consistent variable parameter Muskingum-Cunge approach. Hydrol. Earth Syst. Sci., 11, 1645-1659, https://doi.org/10.5194/hess-111645-2007.

Trenberth, K. E., A. Dai, R. M. Rasmussen, and D. B. Parsons, 2003: The changing character of precipitation. Bull. Amer. Meteor. Soc., 84, 1205-1217, https://doi.org/10.1175/BAMS-84-9-1205.

Veilleux, A. G., T. A. Cohn, K. M. Flynn, R. R. Mason Jr., and P. R. Hummel, 2014, Estimating magnitude and frequency of floods using the PeakFQ 7.0 program. USGS Fact Sheet 2013-3108, 2 pp., http://pubs.usgs.gov/fs/2013/3108/.

Xia, Y., and Coauthors, 2012: Continental-scale water and energy flux analysis and validation for the North American Land Data Assimilation System project phase 2 (NLDAS-2): 1. Intercomparison and application of model products. J. Geophys. Res., 117, D03109, https://doi.org/10.1029/2011JD016048.

Yang, Z.-L., and Coauthors, 2011: The community Noah land surface model with multiparameterization options (Noah-MP): 2. Evaluation over global river basins. J. Geophys. Res., 116, D12110, https://doi.org/10.1029/2010JD015140.

Zhang, J., and Coauthors, 2016: Multi-Radar Multi-Sensor (MRMS) quantitative precipitation estimation: Initial operating capabilities. Bull. Amer. Meteor. Soc., 97, 621-638, https://doi.org/10.1175/BAMS-D-14-00174.1.

Zhang, Z., V. Koren, S. Reed, M. Smith, Y. Zhang, F. Moreda, and B. Cosgrove, 2012: SAC-SMA a priori parameter differences and their impact on distributed hydrologic model simulations. J. Hydrol., 420-421, 216-227, https://doi.org/10.1016/ j.jhydrol.2011.12.004.

Zheng, H., and Z.-L. Yang, 2016: Effects of soil-type datasets on regional terrestrial water cycle simulations under different climatic regimes, J. Geophys. Res. Atmos., 121, 14 387-14 402, https://doi.org/10.1002/2016JD025187.

Zoccatelli, D., M. Borga, A. Viglione, G. B. Chirico, and G. Blöschl, 2011: Spatial moments of catchment rainfall: Rainfall spatial organisation, basin morphology, and flood response. Hydrol. Earth Syst. Sci., 15, 3767-3783, https:// doi.org/10.5194/hess-15-3767-2011. 